\title{
La vida de Jesús en el evangelio de Juan
}

\author{
JOSEP ORIOL TUÑI V., S.J. \\ Facultad de Teología de Cataluña \\ y Centro de Reflexión Teológica, San Salvador.
}

Una de las nuevas características de la actual reflexión cristológica es el papel que se atribuye a la historia de Jesús. ${ }^{1}$ Se ha hablado asi de una verdadera recuperación del Jesús histórico en la cristología. ${ }^{2}$ Y la diversidad de perspectivas desde donde se han escrito muchas de las cristologías de estos últimos años hace concluir que se trata de una característica "universal," es decir que pertenece a la reflexión cristológica y no sólo a algunos de sus representantes. ${ }^{3}$

Pero también es un aspecto característico de la reflexión cristológica de nuestros días que el evangelio de Juan (EJ) resulta un documento sumamente incómodo y de difícil integración para la misma. Porque, por una parte, su "información" sobre la vida de Jesús es lan diversa de la que ofrece la tradición sinóptica que sólo artificialmente se puede trazar un esquema común. No sólo estamos ante una obra que nada dice acerca de la predicación de Jesús sobre el reino de Dios, que no se refiere para nada a la enseñanza de Jesús en parábolas ni narra exorcismo alguno de Jesús, sino que, además, los datos que proporciona en este sentido parece que nos trasladan a un entorno cultural diverso, con una cronología y geografia del ministerio de Jesús que sólo muy artificialmente pueden ser integradas en el esquema sinóptico. ${ }^{4}$ Por ello, la utilización del EJ en las diversas cristologías sistemáticas es más bien puntual y muchas veces los cristólogos contemporáneos se limitan simplemente a silenciar la información joánica o, como máximo, a utilizarla en determinados momentos. ${ }^{5}$ Con lo cual no se ha justificado el uso general del EJ para rememorar los datos más importantes de la vida de Jesús. ${ }^{6}$

Pero, por otra parte, en un segundo nivel de reflexión, cuando la cristologla ha de dar cuenta de la trayectoria cristológica fundamental del cristianismo naciente, entonces el EJ no sólo es considerado un punto de referen- 
cia legitimo, sino que resulta un punto de referencia obligado. ${ }^{7}$ Es en el EJ donde los primeros pasos del dogma crisıológico fundamental encuentran un punto de apoyo indispensable. ${ }^{8} \mathrm{Y}$ las cristologias apelan a textos bien conocidos y repetidamente citados. Pero entonces uno no puede sustraerse a la impresión de que este uso a nivel dogmático resulta por lo menos cuestionable (por no decir conceptualista). 9

Esta es la ambiguledad fundamental que rodea al uso del EJ en la cristologia: se considera un documento que dificilmente refleja la vida terrena de Jesús, pero, en cambio, su interpretación cristológica se hace indispensable. ${ }^{10}$ A un observador le puede parecer casi cvidente que con ello se está implicando que el $\mathrm{EJ}$ es una reflexión cristológica muy profunda pero para la cual los datos acerca de la vida y de la predicación de Jesús resultan simplemente un marco extrinseco. Parece, en efecto que no hay en el EJ una integración de la vida de Jesús en la reflexión crisıológica; y por consiguiente, que la vida de Jesús no seria más que un mero marco para grandes vuelos teológicos, pero no habría sido objelo de verdadero interés por parte del autor (o autores) del EJ. Estaríamos a un paso de una supuesıa interpretación doceta del EJ.

¿Qué tiene que decir aquí la exégesis joánica? Paralelamente a la dinámica teológica esbozada se encuentra la dinámica de la exégesis joánica. La primera mitad de nuestro siglo se caracterizó en este sentido por la convicción más o menos explicita de que el EJ estaba tan alejado del Jesús terreno, que no sólo no era un documento utilizable para la reconstrucción de la vida de Jesús, sino que más bien correspondia a una comunidad con una filiación de lipo helenistico, ${ }^{11}$ muy alejada de Jesús y de su vida.

En los años 50 se fue imponiendo lo que entonces vino a llamarse el new look, es decir, una convicción más o menos explícita de que el EJ podia ofrecernos una información histórica si no más fiable que la de los sinópticos, por lo menos de la misma categoría. ${ }^{12}$ Ello alcanzó un cénit en la conocida obra de C.H. Dodd sobre la tradición histórica del cuarto evangelio, ${ }^{13}$ la cual algunos calificaron como la obra definitiva. ${ }^{14}$

Pero después de esta breve etapa más optimista, la exégesis joánica tampoco ha sido capaz de integrar la "información histórica" y la reflexión teológica. $Y$ no deja de ser significativo en este sentido que los últimos 20 años han ido corriendo el centro de interés de la cuestión de la historia de Jesús ${ }^{15}$ hacia una consideración mucho más centrada en la historia de la comunidad. ${ }^{16} \mathrm{De}$ modo que, en la práctica, cuando se habla de "historia"' en el marco de la exégesis joánica actual, se está haciendo referencia a la historia de la comunidad. 17 Y resulta notoria la ausencia del tema de la historicidad de Jesús en el horizonte de la exeggesis joánica actual.18

Con ello, insensiblemente, la exégesis del EJ ha ido dando la razón (por lo menos de un modo implícito) a una interpretación "monofisista") de la cristología jónica, 19 acorde con la ambigüedad denunciada en la utilización del EJ en las cristologías contemporáneas: la presentación de la cristología jó́nica no parece haber sabido integrar la "historia de Jesús" y la reflexión cris- 
tológica. ${ }^{20}$ Por ello, como lo ha formulado provocativamente la exégesis contemporánea, la cuestión fundamental de la intepretación del EJ es si su cristologia está peligrosamente abocada a la gnosis.21

Nos hallamos, por tanto, ante un aspecto importante tanto de la reflexión cristológica contemporánea como de la misma exégesis joánica. Ante un problema de estas dimensiones no podemos pretender, en este breve estudio, resolver todos los aspectos implicados. Por ello, quisiéramos abordar el problema global, cuál es el sentido de la vida de Jesús en el EJ, desde la perspectiva de totalidad que preside la presentación joánica. ${ }^{22}$ Con ello pretendemos modestamente abrir un camino quc quiere tener dos dimensiones: facilitar la integración de la cristologia joánica en la reflexión cristológica aclual y, además, intentar contribuir a la interpretación de la misma cristologia joánica.

Dos observaciones ayudarán al lector a situarse ante la problemática de este trabajo. En primer lugar, tanto la exégesis como la reflexión cristológica han trabajado, en el estudio del Nuevo Testamento, con un presupuesto muchas veces implícito, pero profundamente condicionante: las obras del Nuevo Testamento pueden proporcionarnos una serie de daios históricos sobre Jesús. ${ }^{23}$ Naturalmente los evangelios ocupan aqui un lugar preeminente; e indudablemente el presupuesto es legitimo. Pero el problema planteado es muy complejo. Porque en la práctica se identifica "historicidad" con "información histórica," y de hecho se valora la historicidad de las obras neotestamentarias por la cantidad de información histórica que proporcionan sobre Jesús. Se hace entonces una ecuación muy sencilla: "información histórica" igual a valor histórico. ${ }^{24}$ La reflexión actual sobre el Jesús histórico y su recurso casi exclusivo a los evangelios sinópticos muestra precisamente como este criterio ha sido determinante.

Pero uno puede preguntarse si la aplicación práctica de este criterio no deja entrever una concepción demasiado positivista de la historia. Y si, de hecho, supuesta la revalorización de los "autores" de los evangelios (y de su intención en la redacción de los mismos), no se debería tener mucho más en cuenta el significado de "lo histórico" para el redactor. Porque entonces, para poner un ejemplo patente, a pesar del mayor interés de Lucas por "la historia," sin embargo, la innovación historificante de Marcos atribuye a la historia de Jesús un valor mucho más relevante que aquél: se convierte en una tesis del segundo evangelio. ${ }^{25} \mathrm{Y}$ ello independientemente de la cantidad de información que estos "autores" hayan recogido y reproducido en sus obras. Es el talante "historico" de cada autor lo que debe de ser valorado.

Por consiguiente, parece que un primer criterio para valorar "la historia" de los evangelios debería ser cómo valora cada uno de ellos "la historia." $\mathrm{O}$, si se quiere, cuál es el concepto de "historia" para cada autor evangélico. Porque en los evangelios (en contraste con las "formas" que están a la hase de los mismos)hay que contar con el talante histórico de los "evangelistas." Dentro de este enfoque la pregunta por la cantidad de información histórica ocupa un lugar claramente subordinado. Y no podemos decir que uno de los evangelios sea más histórico que otro. El valor histórico de la obra ( $y$, por tanto, el senti- 
do de la historia de Jesús en cada autor) vendrá más bien marcado por el interés y papel de lo histórico para cada autor. ${ }^{26}$ Esto abre el horizonte a olra consideración sumamente importante que debemos tratar aparte.

Los evangelios sinópticos presentan (sobre todo si tenemos en cuenta la llamada teoría de las dos fuentes) una forma de valoración de "lo histórico." Los gestos y las palabras de Jesús tienen según ellos ( $y$ con matizaciones importantes) ${ }^{27}$ una función clara y definida, recuperar la praxis de Jesús para los lectores. Sin embargo, nadie se atreverá a negar que es posible recuperar la praxis de Jesús de otra manera; $y$, por lo tanto, valorar la "vida de Jesús" desde otros puntos de vista y desde otros intereses. Al fin y al cabo el carácter de "hechos históricos" de la vida de Jesús la convierte en dato abierı.

A la luz de esta sencilla consideración puede ser intcresante recordar que el Nuevo Testamento presenta esquemas muy diversos de recuperación de la vida rerrena de Jesús. Para poner algunos recordaremos la llamada carta a los Hebreos y la primera carta a Pedro.

A pesar de su carácter altamente teológico, la carta a los Hebreos considera los dias mortales de Jesús como garantía indispensable del anuncio de una salvación ya alcanzable: tenemos el acceso abierro a Dios ahora (Heb. 10, 19 $23 ;$ cf. 3,13$)$ y Jesús es la garantía de este acceso $(7,22)$. ${ }^{28} \mathrm{El}$ acento de Hebreos está en que el acceso se ha hecho posible porque uno de nuestra raza, Jesús, ha alcanzado un lugar permanente junto a Dios (2,5-18). Si Jesús ha vivido nuestra vida $(2,14)$, entonces nosotros podemos entrar con él y por él cn el santuario celestial $(4,14.16)$, precisamente porque compartimos su misma vida y podemos, por lo tanto, compartir su muerte. La realidad de Jesús de Nazaret es subrayada en este escrito mediante el mismo nombre. "Jesús" $(2,9 ; 3,1$; $4,14 ; 6,18-20 ; 7,22 ; 10,19 ; 12,2-3 ; 12,24 ; 13,12 ; 13,20)$. Un escrito literariamente tan sofisticado como Hebreos habla en términos sumamente sencillos, y a aquél que es el sacerdote por excelencia del nuevo culto $(3,1 ; 4,14$; $8,1 ; 9,11 ; 10,21)$, ${ }^{29}$ el que está a la derecha de Dios, lo llama simple y llanamente así, "Jesús." Y presenta los días terrenos de Jesús con trazos duros y grandemente "abajados:" Jesús gime y se debate ante la muerte $(5,7-8)$, está rodeado de debilidad $(5,2)$, vive su vida en constante tentación $(4,15)$ y padece la muerte $(2,9)$. Jesús es quien ha comenzado y llevado a plenitud la misma fe que tenemos nosotros $(12,2)$, por ello nuestra consumación está garantizada como la suya y por la suya $(12,1)$.

Estos trazos de Hebreos son una muestra suficiente de una recuperación muy profunda de la "vida de Jesús." Si bien los datos biográficos son minimos (cf. 2,$3 ; 5,7-8 ; 7,14 ; 13,12),{ }^{30}$ el lector está invitado a vivir "teniendo los ojos fijos en Jesús" $(12,2)$, está invitado a contemplarlo $(2,9)$, a acercarse a él $(4,16$; cf. 10,22). Aquí conviene subrayar que el género literario utilizado para presentar este misterio que da sentido a la vida cristiana no tiene que ver con el género literario de los sinópticos, y, sin embargo, ha hecho una profunda relectura de la existencia terrena de Jesús. Ha recuperado a Jesús y su vida terrena para la comunidad. Pero lo ha hecho de otra manera. ${ }^{31}$ 
Algo parecido ocurre con la primera de Pedro. 32 En este escrito una comunidad sencilla, en visperas de persecución, es exhortada a considerar el sufrimiento de Jesús no sólo como modelo del sufrimiento de la comunidad, sino como inspirador de una manera concreta de sufrir (y también de morir). Sul'rir como Jesús no sólo quiere decir imitarlo, sino que también quiere decir sufrir de la forma concreta como Jesús padeció en su pasión (2,21-24). De aquí la importancia de los himnos del Siervo de Yahvé, que constituyen la clave de lcctura del sufrimiento histórico de Jesús $(4,1-2 ;$ cf. 3,18$)$. Por tanto, cuando la carta de Pedro habla del sufrimiento de Cristo no hace referencia a un Cristo cosmico, cuyos sufrimientos se alargan en la comunidad creyente (cf. Fil. 3,10). Está hablando del sufrimiento histórico de Jesús y de su fuerza inspiradora para el sufrimiento cristiano: "han sido llamados a seguir sus huellas" $(2,21)$.

En la primera de Pedro nos encontramos,por lo tanto, ante una clara "memoria hisıórica" de la comunidad. Esıa pone al lector ante el sufrimiento histórico de Jesús, en la medida que éste inspira la vida y también la muerte cristiana: "si sufren a causa de ser cristianos, no se desanimen, más bien glorifiquen a Dios a causa de este nombre" $(4,16)$. También aquí, como en Hebreos, estamos muy lejos de las presentaciones sinópticas. A pesar de ello, dificilmente se entenderá el mensaje de la primera de Pedro sin el recuerdo del sufrimiento histórico de Jesús: "habiendo padecido él en su condición humana, también ustedes han de revestirse de la misma actitud interior... él, que cuando lo insultaban no devolvía el insulto; mientras padecia no profería amenazas; al contrario se ponía en manos del que juzga rectamente" (4,1; $2,23-24)$. $^{33}$

Hasta aquí dos ejemplos de recuperación de la vida terrena de Jesús hechos con una motivación y de una forma bien diferentes de la presentada por los evangelios sinópticos. Y, sin embargo, también para Hebreos y para la primera de Pedro, la vida terrena de Jesús tiene un sentido y una función bien precisas. ${ }^{34}$

En este contexto vamos a preguntarnos por el sentido y la función de la vida de Jesús en el EJ. Es aqui, por lo tanto, donde hay que situar nuestras pregunlas: ¿cuál es el sentido de la presentación narrativa del EJ? ¿De dónde le viene a) EJ la presentación de su cristología de acuerdo y con los trazos fundamentales de la vida de Jesús? ¿Le viene de un mimetismo extrínseco, el cual ha conocido la forma de "evangelio" y simplemente la ha copiado de alguno de sus predecesores? ¿Hasta qué punto ha integrado el EJ la vida de Jesús en su mensaje cristológico? O no habrá que preguntarse, formulándolo en términos exegéticos del EJ, ¿estamos ante un conjunto de meditaciones sobre el Logos "maquilladas" de evangelio? ${ }^{35}$

Nuestro presupuesto fundamental es el siguiente. Es probable que en el EJ haya un interés por la vida de Jesús que no se amolde ni a nuestro concepto de historia ni tampoco exactamente al interés por la vida terrena de Jesús de ninguna de las otras obras que forman el Nuevo Testamento. Es con esta pregunta - y con esta hipótesis - que vamos a dirigirnos al EJ para ver si, a través de su cristologia, podemos alcanzar el sentido fundamental de su presentación 
narrativa. Con ello, como hemos indicado más arriba, pretendemos por encima de todo hacer legitima la utilización del EJ en la reflexión del sentido fundamental del Jesús histórico en la cristologia. Y más concretamente, en la cristologia latinoamericana, porque es aquí donde más fructuosamente se ha recuperado la vida terrena de Jesús para la cristología y la vida cristiana y es aqui donde el EJ puede ser integrado con mayor profundidad.

\section{La reflexión cristológica joánica}

El aspecto más sobresaliente en las presentaciones cristológicas de la exégesis joánica de estos últimos años es que el EJ refleja una verdadera trayectoria cristológica. ${ }^{36}$ Esta trayectoria parte de unos comienzos muy sencillos y va madurando poco a poco hasta ofrecer una cristología muy elevada, en la cual la llamada preexistencia de Jesús ocupa un lugar destacado.

Pocos exegetas negarán la existencia de una verdadera historia de la cristología joánica, y en algún sentido, es importante tener en cuenta este progresivo desarrollo de la cristología, por lo menos para no caer en una explicación "mágica" de la misma. ${ }^{37}$ Sin embargo, lo que no acaba de quedar claro en esta progresiva elaboración de la cristologia joánica es dónde hay que ponerle el catalizador definitivo. $O$, si se quiere, icuál es el rasgo fundamental que confiere a esta cristología su carácter especificamente joánico?

Ciertamente hay que contar con múltiples factores en el progresivo desarrollo y maduración de la reflexión cristológica de esta comunidad. A una primera etapa de cristología primitiva, que presenta a Jesús con los rasgos del "hombre celestial," 38 hay que sobreponer una segunda capa de tradición formada principalmente por los datos de la reflexión comunitaria, la cual deslinda la significación de la persona de Jesús frente a la importancia decisiva de Moisés para la sinagoga farisea. 39 Por otra parte, hay que contar con la contraposición Jesús-Juan Bautista en la medida que ésta ocupa un lugar bien patente en la estructuración de la presentación cristológica joánica. ${ }^{40} \mathrm{Y}$ no podemos olvidar tampoco el claro in llujo de las tradiciones samaritanas en la configuración de esta cristologia. ${ }^{41}$

Todo esto es verdad y probablemente hay que contar con muchos otros influjos, dado el largo período de tiempo en el cual se fue gestando el EJ y las diversas etapas que caracterizaron esta gestación. Sin embargo, nuestra pregunta va más allá de todos estos componentes de la cristologia joánica. ¿No será posible, más allá de todos estos rasgos, dar con un aspecto más profundo que constituya la clave última de la reflexión cristológica de esta comunidad? Al fin y al cabo muchos de los rasgos mencionados tienen también su papel en otras cristologías neotestamentarias (basta pensar en la cristologia de la carta a los Hebreos y sus innegables afinidades con la cristologia del EJ). Nuestra pregunta quiere ir más allá y podria formularse así: ¿qué es lo que en definitiva convierte la reflexión cristológica de esta comunidad en una reflexión cristológica específicamente joánica? ¿Cuál es la clave de la presentación de Jesús que tenemos en el EJ? 


\subsection{La clave de la presentación cristológica del EJ}

En primer lugar, el EJ hace patente una clara conciencia de estar alejado del Jesús terreno: "lo que distingue a Juan de los sinópticos es que siente la distancia que lo separa del Jesús histórico y reflexiona sobre la misma en un grado más intenso que los sinópticos." 42 Y es precisamente en los texios en los cuales la distancia aparece más clara donde se haya el punto clave de la reflexión cristológica joánica. Veamos estos textos con cierto detalle.

El primer texto que vamos a considerar se halla al final de la primera aparición de Jesús en Jerusalén, después de la expulsión de los vendedores de templo (Jn. 2, 13-22). A la pregunta de los judios por la "autoridad" para hacer aquel gesto profético (cf. la versión sinóptica en Mc. 11,28 y par.), Jesús responde con un dicho enigmático sobre el santuario, "destruyan este santuario y yo lo levantaré (resucitaré) en tres dias" $(2,19)$. El texto presenta a continuación el malentendido de los judios: "Cuarenta y seis años se han tardado en construir este santuario, iy tú lo vas a levantar (resucitar) en tres dias?" $(2,20)$. Es a partir de aquí cuando se percibe con mayor claridad el trabajo de interpretación del EJ, el cual se ve en la necesidad de hacer dos cosas. En primer lugar, dar el sentido del dicho enigmático de Jesús y luego explicar cómo se ha llegado a alcanzar este sentido: "pero él hablaba del santuario de su persona (cuerpo). Ya que, cuando resucitó de entre los muertos, se acordaron sus discípulos de que dijo esto, y creyeron en la estrictura y en la palabra que dijo Jesús"' $(2,21-22$; $c \Gamma$. la cita escriturística en 2,17$)$. He aquí, por tanto, un texto que no esconde su origen postpascual y que considera la experiencia de la pascua (cf. el comienzo de la escena: "estaba cerca la fiesta de la pascua de los judios," 2,13) como un dato esencial para la intrepretación de la palabra ( $\mathrm{y}$ también indirectamente del gesto) de Jesús. El comentario se debe a quienes saben el final de la historia, a quienes conocen por experiencia propia el verdadero alcance de las palabras de Jesús, precisamente gracias a la luz de la pascua." 43

Tenemos aquí un primer texto muy significativo. El sentido cristológico del gesto sólo se develó a los discipulos con la resurrección de Jesús. Más aún, es el "recordar" las palabras (y el gesto) de Jesús lo que constituye la base de la presentación cristológica. Podemos decir, por lo tanto, que la memoria histórica de los discípulos se hace un momento esencial de la reflexión cristológica, y que esta memoria ha sido evocada a la luz de la resurrección.

El segundo texto que nos interesa se halla en la última visita de Jesús a Jerusalén (Jn. 12,12-16), con un claro paralelo también en la tradición sinóptica (Mc. 11,1-11). La muchedumbre recibe a Jesús con aclamaciones y éste sube a un asno para entrar en la ciudad, cumpliendo asi la profecia de Zacarías $(9,9)$. El lexıo joánico es muy austero; $y$, sin embargo, el comentario no puede ser más explícilo: "al principio sus discípulos no cayeron en la cuenta de ésto, pero cuando Jesús fue glorificado se acordaron de que estas cosas estaban escritas sobre él y de que ellos (los mismos discipulos) le habian hecho esias cosas" $(12,16)$. A pesar de que se trata de una anotación poco clara ( $i e s$ que acaso la muchedumbre que aclamaba a Jesús comprendió ya entonces el sentido del 
acontecimiento y en cambio sólo los discípulos no lo comprendieron?) ${ }^{44}$ proporciona también la clave del sentido cristológico de la acción: el recuerdo a la luz de la glorificación de Jesús. La memoria suscitada por la glorificación de Jesús. Nos encontramos con la misma óptica detectada en el texto anterior. El sentido cristológico de los gestos de Jesús sólo se hace patente a los discípulos con la glorificación (resurrección) del mismo Jesús.

Un tercer texto puede ser clasificado con los dos anteriores, a pesar de algunos aspectos menos claros. Se trata de la visita a la tumba de Jesús por parte de Pedro y del otro discípulo: "entonces entró también el otro discípulo, que había llegado primero al monumento, y vio y creyó; pues todavía no habían entendido la escritura (que dice) que tenía que resucitar de entre los muertos" (20,8-9). El texto tiene una seria inconsistencia en la cual no vamos a insistir, pero que es necesario mencionar. Primero se nos habla de la fe del discípulo quien habia llegado antes al monumento y entró después de Pedro. Y a continuación -iprecisamente a continuación! - se dice (en plural) que todavía no habían entendido la escritura que dice que debia resucitar de entre los muertos. La secuencia no tiene lógica. A no ser que el texto quiera implicar que Pedro no llegó a la le. Pero, entonces, ipor qué poner el texto en plural, cuando se acaba de afirmar inequivocamente la fe del otro discipulo? ${ }^{45}$ A pesar de esta inconsistencia de texto, podemos clasificarlo junto con los anteriores, precisamente, porque subraya que el conocimiento del sentido del texto veterotestamentario - sea cual sea el momento en que se alcance- sólo adviene a los discípulos con la resurrección de Jesús. Pero, notémoslo, no mecánicamente. La resurrección de Jesús no es una transparencia automática, sino que conlleva un proceso de iluminación. Recordemos que la exigencia hermenéutica de los sucesos pascuales fue muy superior a las necesarias adaptaciones de los mismos a sucesivas situaciones y comunidades. ${ }^{46}$ Es en este sentido que la resurrección-glorificación de Jesús resulta un punto de referencia esencial de la peculiar interpretación cristológica de la comunidad joánica.

De aquí que de los tres textos presentados podamos sacar una consecuencia importante de cara a nuestra indagación: el EJ se ha escrito a la luz de la glorificación de Jesús. Y muchos textos del EJ sólo se pueden comprender plenamente si tenemos en cuenta este carácter de operación hermenéutica que constituye el meollo de la presentación cristológica de este evangelio. El EJ aparece así como la obra de una comunidad que relee la vida de Jesús a la luz de la pascua 47

Al lector familiarizado con la exégesis neotestamentaria y con la reflexión cristológica esta consecuencia puede parecerle evidente. Pero hay que notar algo característico y peculiar de la presentación joánica: este horizonte hermenéutico no se presenta como exigencia dogmática a priori. Se presenta como clave de lectura que proporciona el mismo EJ. Y por lo tanto, es la clave hermenéutica. Podriamos decir que se trata de un dato esencial para la lectura y comprensión del EJ, sobre todo en la medida en que se trata de un dato intrinseco al mismo EJ, del cual no se puede prescindir si queremos captar el talante más profundo de esta obra. En este sentido constituye un punto de referencia insoslayable de cara a comprender su cristología. Y, de hecho, es la clave más profunda de la misma. Veámoslo más despacio. 
EI EJ no se contenta con hacer una determinada relectura de los gestos y de las palabras de Jesús. En un buen número de lugares proporciona su fuente de inspiración, da al fundamento último de su peculiar relectura de la vida de Jesús. Es el punto de mira desde donde se ha hecho la interpretación de los gestos y las palabras de Jesús lo que nos interesa. Y esta obra no lo ha mántenido en secreto, sino que lo ha hecho plenamente explicito: la fuente de inspiración de la relectura de la vida de Jesús es el Espíritu.

Hay un texto del EJ que resulta decisivo en este sentido: "esto lo dijo refiriéndose al Espiritu que iban a recibir los que habian de creer en él. Porque todavía no estaba el Espiritu porque Jesús no habia sido glorificado"' $(7,39)$. La acción del Espiritu durante la vida de Jesús se refiere exclusivamente al mismo Jesús: es él quien va a bautizar en Espíritu (1,32-33; cf. 3,3-5 y 3,22), y es él quien está lleno del Espíritu (3,34). Los creyentes, en cambio, sólo participarán del Espíritu como don de Jesús resucitado (glorificado).

Recordemos, antes de entrar de lleno en este tema, que es un dato proverbial de la interpretación del Nuevo Testamento que la fe sólo se hace realidad con el don del Espíritu. Los teólogos neotestamentarios que han elaborado una doctrina del Espíritu estarian fundamentalmente de acuerdo con un dato que más tarde pasó a funcionar como dato dogmático. La visión lucana presenta este punto con mucha solemnidad en la efusión de pentecostés que convierte a los atemorizados apóstoles en decididos misioneros. Pablo, por su parte, considera que el don del Espíritu nos introduce en la condición de hijos adoptivos: se trata de las primicias de los salvados en esperanza.

En este punto (como en otros aspectos verdaderamente centrales del Nuevo Testamento) el EJ viene a coincidir fundamentalmente con la visión de otros teólogos neolestamentarios. El cristianismo, propiamente hablando, sólo comienza con la venida del Paráclito (que es el Espíritu Santo), ${ }^{48}$ y, por lo tanto, no hay participación de la vida eterna ( no puede haberla!) antes de la glorificación de Jesús. Porque, en definitiva, uno de los aspectos más importantes de este complejo acontecimiento que el EJ denomina la "glorificación de Jesús" es precisamente el don del Espíritu. Que este don está intimamente unido a la muerte de Jesús lo muestra la afirmación "y entregó el Espiritu" $(19,30)$, una afirmación de doble sentido (muerte de Jesús y entrega del Espíritu a los creyentes), pero bien significativa si tenemos en cuenta el texto citado más arriba $(7,39)$ y que, además, ha sido clarificada en $1 \mathrm{Jn} .5,6-8$, donde el don del Espiritu es indisolublemente unido a la muerte de Jesús (mención del Espíritu junto a la efusión de sangre y agua, cf. Jn. 19,35-37). Por otra parte, el don del Espiritu ha sido enlazado con Jesús resucitado (glorificado) en el conocido texto de Jn. 20,22: "y diciendo esto sopló sobre ellos y les dice: reciban el Espíritu Santo."

Por lo tanto, sólo con la venida del Espíritu a los creyentes será posible la mirada retrospectiva y reposada sobre los gestos y las palabras de Jesús para desentrañar su verdadero sentido. Esto es lo que nos dice explicitamente el EJ: "... es él quien les enseñará todas las cosas y les hará recordar todas las cosas que yo les he dicho"' $(14,26$. Respecto de Jesús (es decir, en la línea de la re- 
flexión cristológica de la comunidad), el Paráclito es quien devela el sentido de lo que Jesús ha dicho y hecho (las palabras y las acciones de Jesús son idénticas). Y para ello ha de traer a la memoria la vida de Jesús. Este develar el sentido y traer a la memoria es precisamente lo que hemos encontrado en los textos analizados antes: "se acordaron los discípulos" (2,22; 12,16; cf. 20,9). El recuerdo de los discípulos es causado (los verbos utilizados están semánticamente relacionados) por el "hacer recordar" o traer a la memoria del Parácli10. 49

Hay otro texto, entre los fragmentos sobre el Paráclito, que resulta especialmente importante en este sentido: "cuando venga él, el Espiritu de la Verdad, les conducirá a la verdad completa. Porque no hablará por su propia cuenta, sino que dirá las cosas que haya oído... él me glorificará, por cuanto recibirá de lo que es mío y se lo anunciará" (16,13-14). La acción del Paráclito de cara a los discipulos es conducirlos al pleno conocimiento del misterio de Jesús. Y el contenido del misterio de Jesús es algo que el Paráclito recibe porque ha sido dado ya en la vida de Jesús: son los gestos y las palabras del mismo Jesús. Sobre esto versará su revelación a los creyentes.

La conclusión prácticamente evidente de estos textos es que el Espíritu es el verdadero intérprete de la tradición de la comunidad joánica ${ }^{50}$ Es él quien hace recordar, quien enseña el sentido de la vida de Jesús. En definitiva, por lo tanto, es él quien pone en marcha la reflexión cristológica de la comunidad. Sin el Espiritu la vida de Jesús es opaca, está abierta al malentendido y a la incomprensión. Sólo la acción del Espiritu da la verdadera medida de la identidad de Jesús para la comunidad joánica.

Sea cual sea la trayectoria de la reflexión cristológica comunitaria, sólo con el don del Espíritu comienza la verdadera reflexión cristológica joánica como tal. La cronología de esta reflexión es menos importante de lo que muchos piensan porque, en último término,la reflexión cristológica joánica sólo se dará con el Paráclito. He aquí, pues, la clave que buscábamos. No es sorprendente el que sea un dato más teologal que histórico porque es una obra cuyo interés central es la teologia.

Quisiéramos añadir a esta argumentación una reflexión paralela para complementar y confirmar nuestra conclusión.

\subsection{Reflexión cristológica y misterio de Jesús}

La clave de la reflexión cristológica joánica es el Paráclito. Esta enseñanza del EJ es presentada por el mismo evangelio desde otro ángulo: la cristología, en cuanto reflexión de la comunidad sobre el misterio de Jesús, sólo puede comenzar cuando este misterio ha llegado a su plena realización. ${ }^{\text {1 }}$ Es decir, el EJ no presenta una reflexión cristológica que, por decirlo de alguna manera, acompaña cronológicamente a Jesús a lo largo de su vida. La reflexión cristológica tiene como objeto el misterio de Jesús ya plenamente realizado; $y$, por consiguiente, hay un momento privilegiado en el cual la comunidad puede comenzar a saber y comprender el misterio de Jesús. Veamos esto un poco más en detalle. 
El EJ subraya de diversas maneras la existencia de un momento en el cual se da el conocimiento de la verdad de un modo profundo y claro: "cuando hayan exaltado al hijo del hombre, entonces comprenderán que yo soy..." $(8,28)$. En este texto sobre la exaltación de Jesús la referencia a la cruz resulta patente: "cuando ustedes hayan exaltado..." Para comprender el misterio de Jesús hay que esperar a su muerte.52 Los textos de la exaltación (3,13-14; 12,32-34) enlazan la fe y la comprensión con la contemplación del exaltado (cf. 19,35-37). En otros lugares del EJ, el tema aparece en el contraste entre el "ahora" de la incomprensión (es el "ahora" de la vida de Jesús según la presentación joánica) y el "después" de la comprensión y de la fe plenas; "ahora se los digo, antes de que suceda para que, cuando haya sucedido, crean que yo soy" $(13,19)$. A la luz de estos textos se puede comprender el sentido de la respuesta de Jesús a Pedro: "lo que hago ahora tú no lo entiendes, lo comprenderás después" $(13,7)$. Y en otro lugar: "allá donde yo voy no puedes seguirme ahora, me seguirás más adelante" $(13,36)$. A estos textos se puede añadir la afirmación de Jesús sobre el último dia: "aquel día conocerás que yo estoy en el Padre y ustedes en mí y yo en ustedes $(14,20) .53$

Algunos de los textos citados hacen referencia a una comprensión más profunda. Es este un aspecto importante en la presentación joánica. Porque el tema del conocimiento del misterio de Jesús va de la mano del tema de la fe en el mismo Jesús. Fe y conocimiento no son dos realidades separables, por lo menos en la medida en que tienen el mismo objeto..$^{54} \mathrm{El}$ conocimiento del misterio de Jesús sólo podrá ser realidad cuando Jesús haya recorrido toda su trayectoria. De forma que sólo con la exaltación de Jesús será posible tanto la fe como el conocimiento. Esto se hace patente en los muchos textos donde se pone la fe y el conocimiento paralelamente. Vamos a citar los más claros:

- la confesión de los samaritanos dice: "ya no creemos por lo que tú nos has dicho, pues nosotros mismos lo hemos oído y sabemos que éste es el salvador del mundo" $(4,42)$;

- dice Pedro como portavoz de los discípulos: "nosotros creemos y sabemos que tú eres el Santo de Dios" $(6,69)$;

- Jesús exhorta a la fe diciendo: "crean en las obras para que conozcan y sepan que el Padre está en mí y yo en el Padre" (10,38);

- los discípulos, al final de los discursos de despedida, dicen a Jesús: "ahora sabemos que tú lo sabes todo... por ello creemos que has salido de Dios" $(16,30)$;

- Jesús en su oración al Padre, dice: "ellos han conocido que he salido de junto a ti, y han creldo que tú me has enviado" $(17,8)$.

Lo que podemos deducir de estos texios es que, sin dar al término "conocer" un sentido exclusivamente racional, la experiencia creyente del grupo joánico tiene una componente importante de relexión, o, lo que es lo mismo, una componente notable de comprensión del misterio de Jesús. 55 Esto es lo que dicen textos bien conocidos del EJ, como por ejemplo: "esta es la vida eterna, que te conozcan a ti, único Dios verdadero y aquél a quien enviaste, JesúsMesias" $(17,3)$. Y también, "si permanecen en mi palabra serán verdaderamente discipulos míos, y conocerán la verdad, y la verdad los hará libres" $(8,31-32)$. 
La reflexión cristológica acompaña, por lo tanto, a la experiencia creyente. Es como un momento estructural de la fe. ${ }^{56}$ No se puede dar la experiencia de la fe sin que al mismo tiempo haya una captación del misterio de Jesús. Y para que esto sea posible, el misterio de Jesús ha de haber alcanzado su realización plena.

Con lo dicho en estos apartados queda suficientemente establecido que la reflexión cristológica de la comunidad joánica sólo adquirirá su especificidad joánica en la medida en que esta comunidad haya recibido y experimentado la luz del Espíritu, es decir, que haya alcanzado el nivel de la fe y la comprensión. Ahora bien, si nuestra pregunta inicial hacia referencia a la importancia y al papel de la vida de Jesús en la experìencia de esta comunidad, será en este contexto en el cual deberemos preguntarnos por la misma. Conviene, por eso, preguntarnos por el papel y el sentido de la vida de Jesús, de su terrenalidad, en el contexto de esta reflexión cristológica.

\section{El sentido de la vida de Jesús en la reflexión cristológica de la comunidad joánica}

¿Quién es Jesús para la comunidad joánica? A la luz de lo indicado en los apartados anteriores, esta pregunta tiene un primer nivel de respuesta bien claro y preciso: Jesús, para la comunidad joánica, es aquel a quien la comunidad cree y a quien confiesa como Señor $(20,28)$. Jesús es la razón última de la vida confiada de la comunidad. La fe de esta comunidad, su confianza inquebrantable que define y conforma la vida de la misma, tiene un objeto bien preciso: Jesús. La comunidad habla de Jesús en la medida que este Jesús es creído y confesado, ${ }^{57}$ y nunca al margen de esta confesión. Por lo tanto, sólo en el contexto de la confesión de Jesús como Señor podemos preguntar por el papel y sentido de la vida de Jesús para la comunidad joánica.

Pero hay más. Si Jesús, según el EJ, es aquél que es creído y confesado, entonces, inevitablemente, es también quien está presente. Es quien habla e instruye a la comunidad aqui y ahora. $Y$, por consiguiente, parece claro que se trata de Jesús exaltado, el Jesús que ha recorrido toda su carrera y está de vuelta al lugar de origen.

Pero podemos preguntarnos: ¿es realmente asi? ¿Qué sentido tiene entonces que la comunidad, al hablar del Jesús presente y, por lo tanto, exaltado, nos lo describa con los trazos más importantes de su vida terrena? La reflexión cristológica joánica es más compleja de lo que pudiera parecer a primera vista. Por ello se hace necesario explicitar un poco más los aspectos imporlantes de la misma. Sólo en el marco de la cristología completa de la comunidad será posible percibir el papel y sentido de la vida de Jesús para la misma.

\subsection{El carácter complexivo de la crisıología joánica}

En consonancia con lo que hemos subrayado en los apartados anteriores, y si se quiere, como consecuencia de lo dicho, es necesario explicitar que la cristología joánica se caracteriza, por encima de otros rasgos, por su carácter 
de totalidad, por su carácter de magnitud completa y acabada. La presentación de Jesús que tenemos en el EJ no sugiere una trayectoria cristológica que va recalcando el progresivo perfeccionamiento de Jesús. No asistimos a una $t e-$ leiosis progresiva de Jesús en el EJ. El Jesús presentado en este evangelio es el mismo al comienzo y al final. Habla de la misma manera en las primeras escenas y en los diálogos del relato de su exaltación. Tiene el mismo conocimiento de la realidad en su primera visita a Jerusalén $(2,23-25)$ y en sus discursos de despedida con los discípulos (16,27-337.

Esto lo subrayan con especial énfasis las diversas imágenes y conceptos con que se describe su trayectoria. Tanto la vida de Jesús como su identidad personal se presentan en el EJ con categorías e imágenes complexivas que, lejos de hacer hincapié en distintos aspectos o momentos, recalcan más bien su carácter de totalidad, el cual preside toda la presentación cristológica joánica.

Así, la vida de Jesús es presentada como la "obra" que el Padre le ha dado para ser realizada, "yo tengo un alimento que ustedes no conocen, hacer la voluntad del que me ha enviado y llevar a cabo su obra" $(4,34)$. Jesús habla de su vida en términos de esta obra ya realizada: "te he glorificado sobre la tierra llevando a término la obra que me encomendaste que realizara" $(17,4)$. Dentro de esta visión global no se aprecian aspectos o momentos con especial relevancia. Ni los signos ni el final de la vida de Jesús son concebidos como momentos separadamente significalivos. Y si bien la exaltación de Jesús aparece como un punto culminante de la narración, ello no implica que no haya una profunda integración entre su vida y su muerte. La hora de Jesús no es un momento cronológico, sino que coincide con la entrega de su vida; por eso es, también un claro indicador del carácter de totalidad que preside toda la presentación cristológica del EJ..$^{58}$

Esta visión de conjunto se expresa también mediante el tema de "hacer la voluntad del que me ha enviado" $(4,34: 5,30 ; 6,38$; cf. 10,17-18), el cual se convierte en un verdadero hilo conductor de toda la vida de Jesús en el EJ. 59 Lo mismo cabe decir del tema del "mandamiento" que Jesús ha recibido del Padre. El "mandamiento" recibido no abarca sólo una área especifica de la actividad de Jesús. Todo lo que Jesús hace está comprendido en el mandamiento ("para que el mundo sepa que hago lo que el Padre me ha mandado..." 14,21), pero también todo lo que Jesús dice ("porque yo no he hablado por mi cuenta, sino que el Padre que me ha enviado me ha dado un mandamiento sobre lo que tengo que decir y hablar y yo sé que su mandamiento es vida eterna," $12,49-50$ ). Incluso la misma muerte de Jesús es objeto del mandamiento, en cuanto que es donación de su vida por los suyos (10,17-18; cf. 15,13 ). Es, por lo tanto, toda la vida de Jesús ( $y$ la donación de su vida) lo que abarcan estas descripciones. Lo que caracteriza la presentación joánica es la visión de conjunto, la globalidad.60

Pero no es sólo la vida de Jesús la que tiene este carácter de totalidad. Es su misma persona la que aparece como un todo sin parte. En el EJ la descripción de la persona de Jesús se hace con categorias complexivas, las cuales tienen el mismo carácter de totalidad que caracteriza la descripción de su vida. 
Jesús es, en el EJ, por encima de todo, el enviado y el hijo; y ambas imágenes se utilizan para describir la persona de Jesús como un todo. La misión de Jesús no consiste en realizar unos gestos determinados ni en comunicar un mensaje concreto. Jesús es todo él la misión. No estamos ante un enviado que haya de realizar una tarea determinada. No hay distinción entre Jesús y la misión. En el EJ hay un trazo que distingue la misión de Jesús de cualquier otro tipo de misión: su carácter de totalidad. La misión coincide con la existencia de Jesús. No es algo sobreañadido, sino que define su misma existencia. Su realidad más honda es "ser enviado." Por ello, en no menos de 40 ocasiones se refiere Jesús a su persona como "enviado." La fórmula "el que me ha enviado (el Padre)" pasa a ser en este evangelio un verdadero título de Dios. ${ }^{61}$

Algo parecido hay que decir acerca de la imagen del hijo (y no sólo del título "hijo de Dios"). Con ella el EJ intenta definir la realidad más profunda de Jesús. Y no se limita a describir un aspecto de esta realidad, sino que hace de Jesús el que está siempre en relación de dependencia respecto de su Padre. Con esta imagen subraya que la trayectoria de Jesús comienza en Dios y acaba también en él. Jesús es aquel que "ha salido del Padre y ha venido al mundo, de nuevo deja el mundo y se marcha hacia el Padre" (16,28; cf. 13,1). El camino de Jesús, el hijo, no tiene momentos que sobresalgan sobre otros. Es la realidad de Jesús como totalidad la que se presenta mediante esta imagen tan profunda, la más profunda que ha podido hallar la comunidad para hablar de Jesús. ${ }^{2}$

Hasta aqui un apretado resumen de este carácter complexivo tan profundamente embebido en la presentación cristológica joánica. Pero, entonces, ¿qué decir del esquema cristológico en etapas, caracteristico no sólo de la sistematización de la cristología neotestamentaria, sino también de muchos de sus esquemas? Basta recordar la sólida cristologia de Hebreos o incluso la que subyace en los himnos primitivos como Filipenses 2,5-11, ó 1Timoteo 3,16, para caer en la cuenta de que lo que define al Jesús confesado en estos fragmentos es el pre-existente, pero también el "encarnado" (o "abajado") y al mismo tiempo el exaltado (o el que ha subido). Asimismo parece que estas "etapas" tienen una realidad y una vigencia en el EJ. ¿Es que estamos, en la cristología joánica, ante una confesión que ha hecho "desaparecer" las elapas de la cristología? La vida de Jesús, ¿ha quedado como engullida en un Jesús exaltado atemporal, quien se hace presente a la comunidad, pero cuya vida terrena ha quedado "sublimada" por una transcendencia intocable? ¿Hasta qué punto hay "etapas" en la cristologia joánica?

\subsection{Las "etapas" de la cristología joánica}

A pesar de lo indicado en el apartado anterior, sería muy poco fiel a la presentación joánica decir que las etapas cristológicas han sido borradas de la presentación de la cristología de esta comunidad. En efecto, lanto la cesura marcada por la encarnación ("el Logos se hizo "carne"" 1,14; cl., "yo para eso he nacido y he venido al mundo, para dar testimonio de la verdad" 18,37), como lo que caracteriza la presentación de la muerte de Jesús son muy profun- 
das. Si se quiere, aunque sólo sea porque el acontecimiento de la muerte de Jesús marca la plenificación de su propio misterio y es, por otra parte, el punto de partida de la reflexión cristológica de la comunidad. Es, al mismo tiempo, comienzo y final. ${ }^{63}$ Esto es subrayado específicamente por el don del Espíritu, el cual sólo será realidad después de la marcha (muerte) de Jesús.

Conviene recordar, sin embargo, lo que hemos dicho al comienzo del apartado anterior: que la cristologia joánica es primero y ante todo una cristologia confesada, y que ésta es la cristología del EJ. Por lo tanto, no podemos negar que el Jesús confesado, es decir, el Jesús presente es ante todo el exaltado; porque sólo como exaltado puede ser creido y confesado como Señor y sólo como el que "ha vuelto" puede dar el Espiritu ("les conviene que yo me marche, porque si no me marcho no vendrá a ustedes el Paráclito," 16,7). Jesús, en la comunidad de Juan y en el evangelio de esta comunidad, es, por consiguiente, el exaltado.

Pero, y ahi está la paradoja, el exaltado es tambièn y esencialmente el terreno. Esto se puede mostrar, en primer lugar, recordando que el EJ describe fundamentalmente al Jesús terreno, quien habla y cura y es perseguido y muere. También se puede hacer patente el carácter terrenal del Jesús joánico haciendo referencia a las fórmulas de fe que jalonan todo el evangelio y a los muchos lugares donde la comunidad habla de la fe de los interlocutores de Jesús. En la medida en que en todos estos textos se habla de la fe auténtica (y no hay razones para dudarlo) se está haciendo referencia a la fe de la comunidad. ${ }^{64}$ Son las confesiones de fe de la comunidad las que quedan consignadas en el EJ. No sólo porque de hecho en este evangelio nadie llega verdaderamente a creer en Jesús durante su vida terrena, ${ }^{65}$ sino sobre todo porque la fe durante la vida terrena de Jesús era imposible: faltaba el Espíritu.

En cambio, con el don del Espiritu, adviene a la comunidad la recuperación de la vida terrena de Jesús como contenido de la identidad del Jesús presente confesado como Señor. Por lo tanto, aquí tenemos la recuperación de una etapa aparentemente caducada. Con el don del Espiritu como don del Jesús exaltado ("el Paráclito, el Espiritu Santo que el Padre enviará en mi nombre, él les enseñará lodas las cosas y les hará recordar todo lo que yo dije," 14,26 ) se hace presente a la comunidad el Jesús terreno; porque el presente es el exaltado y el exaltado es el terreno.

La comunidad joánica va todavía más allá, la confesión de la comunidad de Jesús como Señor es también para este grupo la confesión de Jesús como Dios (1,1c; 20,28 y también posiblemente $1,18 \mathrm{cf}$.; $1 \mathrm{Jn}$. 5,20). Ello responde no sólo al tipo de experiencia cristológica que subyace al EJ, sino también a la labor de autentificación de la pretensión del mismo Jesús. ${ }^{66}$ Por eso, la defensa de la autenticidad de la confesión comunitaria frente a una sinagoga que se niega a la fe $(9,22 ; 12,42-43 ; 16,2$; cf. 16,1$)$ lleva a la comunidad a la confesión de lo que tan inadecuadamente hemos de llamar la pre-existencia de Jesús.

Estamos ante una cuestión de legitimación cristológica fundamentalmente. Frente a una sinagoga que pretende ser la única heredera legitima del judaísmo, la comunidad joánica pone a Jesús con Dios desde siempre, porque 
lo que le interesa en definitiva es la legitimidad de Jesús en tanto que enviado de Dios. En este sentido, la comunidad confiesa que Jesús pertenece a Dios desde siempre, que no es fruto de una veleidad histórica. Precisamente por eso puede revelar a Dios. Y lo revela al margen ( $y$, en cierto sentido, en contra) de los canales oficiales establecidos. He aquí el sentido fundamental de la confesión de la preexistencia de Jesús.67

Las etapas no han desaparecido. $Y$, sin embargo, la distinción cronológica de las mismas ha dejado de ser relevante. Las etapas de la cristologia, según la reflexión cristológica de esta comunidad, están todas fusionadas en el objeto de la confesión que es siempre el mismo. La comunidad, al dirigir su confesión al Jesús terreno (recordemos que esto es lo que tenemos en el EJ), está afirmando la identidad de este Jesús terreno con el Jesús exaltado. En la medida que la confesión de Jesús como Señor es también la confesión de Jesús como Dios (cf. 20,28) en esta medida la comunidad joánica esıá también confesando lo que llamamos la pre-existencia de Jesús.

Todo esto se entiende mejor a la luz de la distinción esbozada más arriba: sólo cuando Jesús ha llegado al final de su camino ( $\mathrm{y}$, por lo tanto, sólo cuando desde él se han acabado las etapas de su trayectoria salvifica) comienza, propiamente hablando, la reflexión cristológica de la comunidad ${ }^{68}$ Porque es entonces cuando Jesús se constituye en objeto de la fe y de la confesión de la comunidad, y no antes. Pero precisamente desde entonces el Jesús confesado es siempre el Jesús total. ${ }^{69}$ Para usar otra terminologia: la cristología del EJ, en la medida que es una presentación del misterio de Jesús, está marcada por una implicación cristológica ${ }^{70}$ que liene siempre el mismo sujeto: Jesús-Dios. Las etapas que constituyen la trayectoria cristológica se interpenetran (están proyectadas una en la otra) ${ }^{71}$ en la medida que afectan al mismo sujeto, y están siempre implicadas una encima de la otra. El EJ, sin negar estas etapas como constitutivas de la realidad de Jesús, las hace converger en una magnitud cristológica única, la cual es el objeto de la fe y de la confesión. Se trata de una realidad única, imposible de abarcar: sólo en la medida que es confesada liene sentido y consistencia.

El EJ ha usado una figura bíblica y neotestamentaria especifica para presentar esta implicación cristológica.72 Se trata de la ligura de "hijo del hombre." Es bien claro que esta figura ha sido utilizada para hablar del Jesús exaltado. Todos los texios de la exaltación la usan $(3,13-14 ; 8,28 ; 12,32.34)$. El Jesús exaltado es, en el EJ, por encima de todo el hijo del hombre. Pero esta figura sirve también para resaltar la terrenalidad de Jesús: en tanto que hijo del hombre Jesús puede dar a comer su carne y a beber su sangre $(6,53 \mathrm{cf}, 6,27)$, y es en tanto que hijo del hombre que Jesús va a revelar en la tierra la realidad celestial (3,12-13). ${ }^{73}$ Finalmente este carácter revelador del Jesús joánico liene una ulterior implicación, su origen celestial: "nadie ha subido al cielo sino el que bajó del cielo, el hijo del hombre" $(3,13)$; y en otro texto bien patente: "¿esto les escandaliza? ¿Y cuándo vean al hijo del hombre subir allá donde estaba antes?" (6,61-62). 
Por consiguiente, la clave de todo lo dicho es que Jesús en el EJ es aquél que es confesado como Señor y como Dios. Pero esto es un punto de partida más que un punto de llegada. Y lo es, en definitiva, porque sin la confesión no hay cristologia joánica. Ahora bien, lo peculiar de esta presentación es que ante el lector se pone a Jesús confesado de forma narrativa. La presentación cristológica del EJ apela fundamentalmente a una de las tres etapas que marcan el contenido de la confesión y, por lo tanto, de la cristología: la etapa del Jesús terreno. Por eso lo que tenemos en el EJ es una presentación evangélica de Jesús y no un tratado cristológico. Veamos más detenidamente las caracteristicas de esta presentación evangélica de Jesús en en EJ.

\subsection{El sentido de la presentación del Jesús lerreno en el $\mathbf{E J}^{74}$}

Desde siempre han sorprendido los dalos tan precisos y exactos del EJ sobre la Palestina y, más en concreto, sobre la Judea y Jerusalén de tiempos de Jesús. También resultan sorprendentes los datos cronológicos sobre el "cuándo" han tenido lugar ciertos encuentros con Jesús o han ocurrido ciertos episodios de su vida (y sobre todo su muerte). Por otra parte, la persona de Jesús es presentada con un cierto detalle: se habla de sus padres $(6,42)$, se le conoce como "el hijo de José, el de Nazaret" $(1,45)$, se recalca que es un judio $(4,9)$, que reacciona violentamente ante los abusos del templo $(2,13-17)$, que se fatiga $(4,6)$, que huye $(6,15)$, que se ve obligado a esconderse $(8,59 ; 12,26)$, que lo buscan para matarlo $(5,18 ; 7,1.19 .25 ; 8,37.40)$, que vive como un perseguido $(11,54-57)$, que tiene amigos $(11,5 ; \mathrm{cf} .2,1)$, que llora por la muerte de Lázaro $(11,35.38)$, que se angustia y tiene sed $(12,27 ; 19,28 ; \mathrm{cf} .4,7)$. Todos estos datos conslituyen una descripción bien verosímil y están coronados por la narración de la muerte de Jesús como dato culminante. Este episodio constituye un punto capital de todo el relato de la "pasión" por la manera como el autor ha querido cerlificarlo a través del conocido fragmento sobre la lanza que abre el costado de Jesús (19,31-37). Y si bien el sentido simbólico del mismo no ha escapado a la percepción de la exégesis, sin embargo, su sentido primario es certificar que Jesús murió. 75 Por esto, la lanza abre el costado de Jesús cuando éste ya había muerto $(19,33)$. No se abre el costado para acelerar la muerte sino para evidenciarla. Por eso, el testimonio solemne del discipulo tiene todas las características de una deposición oficial $(19,35)$.

$Y$, sin embargo, el peso del argumento del EJ en este punto no recae sobre los datos en sí. Al fin y al cabo el escrito reconoce que se ha hecho una selección de datos $(20,30 ; \mathrm{cf} .21,25)$, y por lo tanto, el sentido de estos datos no es Irazar una biografia de Jesús. No se trata de reproducir los datos de la tradición para enseñar lo que Jesús hizo y cuándo lo hizo y con qué caracteristicas. Se trata más bien de poner la base de una consideración y una argumentación que van a montarse en otro nivel: el mismo nivel de la confesión de la exaltación y el de la pre-existencia. Y este es el nivel de los principios. Es aquí donde el EJ va a poner el acenio. 76

También aqui se deja sentir el carácter complexivo y global que hemos visto para la crisiologia. Por ello los datos mencionados, lo mismo que la cristologia, se elevan a categoria más complexiva. Si las etapas quedan impli- 
cadas una encima de la otra, también los rasgos que describen la vida de Jesús se confunden unos con otros (obras y palabras de Jesús son idénticas), ${ }^{77}$ hasta alcanzar las formulaciones totalizantes que antes hemos descrito: "hacer la voluntad del que me ha enviado," "llevar a término la obra que el Padre me ha encargado," "realizar el "mandamiento" del Padre."

Sin embargo, estas descripciones no alcanzan todavia el meollo de este aspecto de la cristologia. En consonancia con la dimensión de totalidad y en contraste con la confesión de Jesús como Dios en el EJ se halla explícitamente la afirmación de Jesús como hombre. Este aspecto tan central del EJ merece que le dediquemos una atención especifica.

Los evangelios sinópticos - a excepción de Marcos 15,39- tienen muy pocos textos que expliciten la humanidad de Jesús con el término anthropos ${ }^{78}$ Pero, además, con la excepción apuntada, estos textos sinópticos no tienen significado teológico, en ellos no se pretende recalcar la humanidad de Jesús. Basta citarlos para captarlo: "ha venido el hijo del hombre que come y bebe y dicen: aquí tienen a un hombre comilón y un borracho, amigo de publicanos y pecadores..." (Mt. 1l,19; cf. Lc. 7,34). Por muy escandaloso que pueda resultar el texto a la comunidad, sin embargo, considerado en si mismo no se trata de un texto de especial relieve teológico. El segundo texto se refiere al relato de la pasión, en las negaciones de Pedro: "y de nuevo lo negó con juramento: yo no conozco a ese hombre... entonces él se puso a echar imprecaciones y a jurar: yo no conozco a ese hombre" (M1. 26,72.74; cl. Mc. 14,71). El sentido fundamental del texto es de nuevo peyorativo y también escandaloso para la comunidad, pero no se aprecia en él carga teológica específica. El tercer texto sinóptico se encuentra también en el relato de la pasión. Pilato empleará tres veces la palabra anthropos para referirse a Jesús (Lc. 23,4.6.14). El término designa aqui una cierta distancia, una falta de interés real de Pilato hacia Jesús: éste es un inculpado como cualquier otro, a quien Pilato enviará a Herodes porque pertenece a su circunscripción.

En conjunto no encontramos acento cristológico notable en estos pasajes sinópticos. En cambio, el EJ ha usado este término con mucha mayor amplitud, pero, sobre todo, con una clara conciencia de sus implicaciones en la confesión cristológica.

En primer lugar, hay una serie de textos del EJ que podemos clasificar junto con los citados. Por ejemplo, el de los policias del templo enviados a agarrar a Jesús, quienes vuelven diciendo: "nunca un hombre habló como éste" $(7,46)$. El texto tiene tal vez ciertas implicaciones, pero de suyo no presenta ningún énfasis especial. Lo mismo podemos decir de la discusión entre Nicodemo y los fariseos: " $i$ acaso nuestra ley juzga (condena) a un hombre sin haberlo antes oido y sin saber lo que hace?" $(7,51)$. Naluralmente hace referencia directamente a Jesús, pero de nuevo sin hacer hincapié en su humanidad. Un tercer texto se acerca todavía más a los textos sinópticos. Se encuentra en la narración de la pasión y es una preguntas dirigida a Pedro: “¿no eres tú también de los discípulos de este hombre?" $(18,17)$. Un último texto estrictamente paralelo con los de Lucas citados más arriba: "¿qué acusación traen contra 
ese hombre?" $(18,29)$. Este grupo de textos, considerados en sí mismos, no ofrecen ningún sentido cristológico especial, pero habrá que tenerlos en cuenta después de lo que vamos a decir a continuación, porque entonces adquieren mayor relieve.

El segundo grupo de textos que vamos a considerar se encuentra mayormente en los diálogos de Jesús, es decir, en aquellos fragmentos que más claramente dejan entrever su filiación joánica. Estos textos constituyen un aspecto central del argumento del EJ: cuál es en definitiva la razón más profunda de la condena de Jesús. Como veremos se trata de textos claves para la estructura interna del EJ y, por consiguiente, resultan sumamente relevantes para nuestra investigación:

- 4,29. "Vengan a ver a un hombre que me ha dicho todo lo que he hecho, ¿no será este el Mesías?" Para la mujer samaritana Jesús es un hombre, un judio $(4,9)$, pero puede ser el Mesias. Este contraste puede ser más en lático si tenemos en cuenta que los samaritanos van a confesar que "este (hombre) es el salvador del mundo" $(4,42)$.

- 5,18. En la discusión que tiene lugar después de la curación del enfermo de la piscina de Bethesda comenta el evangelio: "por eso los judios trataban con mayor empeño de matarlo, porque no sólo quebrantaba el precepto sabático, sino que llamaba a Dios su propio Padre, haciéndose a si mismo igual a Dios." El texto hace referencia al versículo 12: "quién es el hombre que te ha dicho: toma (la camilla) y anda." Si Jesús no fuese un hombre, no habría escándalo. Pero en cambio ya se insinúa aqui que la condenación de Jesús vendrá por causa de esta pretensión inaudita, la cual, recordémoslo, es la misma pretensión que se expresa en la confesión de le de la comunidad (cf. además el "hombre" de 5,7 ).

- 8,40. Estamos en plena discusión entre Jesús y los judios sobre la filiación de Abraham, y Jesús les dice: "pero ahora tratan de matarme a mi, un hombre que les a dicho la verdad que he oído junto a Dios." Ordinariamente el EJ presenta a Jesús hablando de lo que ha visto y ódo junto al Padre, no junto a Dios. ${ }^{79}$ Evidentemente, puede haber aquí razones estilisticas. Pero de hecho el texto que hemos citado presenta un coniraste muy claro y enfático: Jesús es un hombre que viene de parte de Dios, a quien los judios quieren matar. Si Jesús fuera un enviado celestial de tipo angélico, ni habría persecución ni los judios podrian intentar matarlo (cᄃ. 5,18 y otros muchos textos donde se menciona la persecución de los judios para matarlo, 7,1.19.25; $8,37.59 ; 10,31$ ).

- 9,11.18.24. Estamos en el diálogo que sigue a la curación del ciego de nacimiento. Cuando los vecinos preguntan al curado quién le ha abierto los ojos, él les responde: "Ese hombre llamado Jesús, hizo barro..." $(9,11)$. Los Tariseos, sin embargo, dicen: "este hombre no viene de Dios porque no guarda el precepto sabático... ¿cómo puede un pecador realizar semejantes signos?" $(9,16)$. Y preguntan al ciego: 
"y tú, ¿qué dices de él?" Y el ciego les responde: "que es un profeta" (9.17). Más adelante, en un nuevo interrogatorio, le dirán: "nosotros sabemos que este hombre es un pecador" $(9,24)$ y el ciego les responderá: "si éste no viniera de Dios, no podría hacer nada" $(9,33)$. La confesión de fe de quien habia sido ciego y su acto de adoración $(9,38)$ coronará este camino de descubrimiento progresivo de la identidad de Jesús. El contraste entre "hombre" y "Dios" se hace patente en este texto.80

- 10,33. Se trata del texto que recoge la acusación de blasfemia de los judios y que, por lo tanio, corresponde al interrogatorio oficial del sanedrín en la versión sinóptica: "no queremos apedrearte por ninguna obra buena sino por una blasfemia, porque tú, siendo hombre, te haces a ti mismo Dios" (cf. Mc. 14,55-64 y par.). Si bien resulta dificil ver exactamente en qué consiste la blasfemia de Jesús en la versión sinóptica, aquí en cambio la acusación judia no deja lugar a dudas. Se han abandonado los títulos mesiánicos y el contraste entre hombres y Dios pasa a primer plano. Estamos ante la acusación más profunda de la sinagoga contra la comunidad: la de convertir a Jesús en un segundo dios al lado de Yahvé. Y es aquí donde la pretensión cristiana queda plenamente al descubierto. ${ }^{81}$ Pero para ello es necesario que se haya tomado plenamente en serio la humanidad de Jesús. Sin ella ni hay escándalo ni condena ni tampoco argumento en el EJ.

- 11,47. Este texto corresponde a la sesión oficial del sanedrin para decidir el caso de Jesús. Los sumos sacerdotes y los fariseos (una expresión bien sorprendente) han reunido el sanedrin. Y decian: "este hombre realiza muchos signos." La respuesta de Caifás es importante: "conviene que muera uno sólo por el pueblo y no perezca toda la nación." Se trata de una muerte, la muerte de un hombre que realiza signos extraordinarios. Y el texto comenta: "esto no lo dijo por su propia cuenta, sino que, como era sumo sacerdote aquel año, profetizó que Jesús iba a morir por la nación" $(11,51)$. Por lo tanto, la muerte de Jesús será para los judios la muerte de un cualquiera. Pero en realidad el acto tendrá otra vertiente, la de la salvación de todos los hombres: "y no sólo por la nación, sino también para reunir en uno a los hijos de Dios que están dispersos" $(11,52)$.

- 19,5.7. Estamos en el centro del relato de la pasión. La solemnidad del momento es literariamente muy enfática. Jesús es sacado llevando la corona de espinas y el manto de púrpura y Pilato dice: "aquí tienen al hombre." Los judios le replican: "nosotros tenemos una ley y según esta ley debe morir, porque se hace a si mismo hijo de Dios." La formulación corresponde a la que hemos visto en 10,33. La utilización del título resulta una adaptación necesaria, dado que se presenta la acusación ante Pilato. Pero la presentación dramática tiene su culminación en el texto paralelo: "aqui tienen a su rey" $(9,14)$. Y esta afirmación va a dar pie a la confesión de la apostasia judia: "no tenemos más rey que el César" $(9,15)$. La palabra rey tiene, pues, una fuerte connotación teológica en estos textos del relato de la exaltación de Jesús. 
Esta serie de textos resulta suficientemente elocuente. La centralidad del tema, por otra parte, queda bien patente por la importancia del mismo tanto en los textos citados como en la misma estructura interna del EJ. De hecho, constituye el meollo de la discusión y de la persecución contra Jesús por parte de los judios. ${ }^{82}$ No estamos ante un tema lateral del EJ. Con el tema de Jesúshombre nos hemos puesto en contacto con el núcleo de la presentación cristológica joánica: con la confesión de la comunidad de Jesús como Dios.

Si la presentación narrativa de este evangelio se hubiera limitado a reproducir los datos de la tradición sobre Jesús, si hubiera hecho una simple reproducción material de gestos y palabras de Jesús, entonces el EJ no habria expresado todo lo que es Jesús para la comunidad. En cambio, en el contexto de la confesión, la realidad terrena de Jesús había de ser afirmada a nivel de doctrina. De este modo, el contexto de la confesión comunitaria proporciona la clave de intelección del sentido de la realidad terrena de Jesús para dicha comunidad.

Es finalmente este contexto de confesión el que confiere su pleno sentido a la afirmación doxológica del prólogo, la cual se acostumbra citar tan a menudo y cuyo sentido sólo adquiere su dimensión plena después de lo que hemos dicho: "el Logos se hizo carne (hombre)." 83 El EJ podía haber prescindido de la referencia al hombre-Jesús si lo que quería era hablarnos de la gloria de Dios y de su presencia entre los hombres. En realidad, Israel lo había podido hacer durante siglos. También podia haber formulado sus afirmaciones fundamentales sobre el Logos divino sin ligarlas a la realidad humana de Jesús. De hecho, el estoicismo lo hizo y Filón de Alejandría también. En cambio, si el EJ consideró necesario afirmar la humanidad de Jesús para hablar de Dios (y este es el sentido fundamental de la confesión) es que no consideró suficiente hablar del Logos. ${ }^{84}$

Hasta aqui un apretado resumen de lo que puede decirse desde la reflexión cristológica de la comunidad joánica. Sin embargo, esta argumentación liene un complemento bien profundo en la vertiente de la vida comunitaria. Si para esta comunidad Jesús es siempre el creído y confesado, entonces, de alguna forma, la comunidad confesante es parte de la cristologia. Si no hay cristologia joánica sin comunidad confesante, entonces la confesión comunitaria resulta un aspecto esencial de la cristologia. ${ }^{85} \mathrm{Y}$ va a ser, de hecho, aquí, donde alcanzaremos con más profundidad el papel y sentido de la vida de Jesús para el EJ.

\section{La vida de la comunidad y la vida de Jesús}

Si en EJ Jesús es el creído y confesado como Señor y como Dios, entonces es también quien está presente en la comunidad. ¿Cómo se describe y justifica esta presencia de Jesús? ¿Cuáles son los trazos que la configuran? Sabemos que la presencia de Jesús es objeto de la actividad del Paráclito, quién hace recordar todo lo que Jesús hizo y dijo. Pero, cabe preguntarse, ien qué medida esta memoria viva de la comunidad, este recordar constantemente la vida de Jesús, configura su vida misma? Veamos este aspecto según uno de los trazos más característicos del EJ, los discursos de despedida de Jesús. 
REVISTA LATINOAMERICANA DE TEOLOGIA

\subsection{La presencia del ausente}

En el EJ el Jesús presente es, el mismo tiempo, quien se ha marchado. Y, sin embargo, es aquél a quien la comunidad confiesa como el centro de su propia vida. La presentación joánica tiene muy en cuenta el carácter paradójico de este Jesús y, por lo tanto, el carácter paradójico de la confesión. Y encuentra en el género literario "discurso de despedida" un medio bien apropiado para iluminar esta paradójica presencia del ausente. ${ }^{86}$ En estos discursos el Jesús presente es el ausente que ha prometido volver, $y$, por consiguiente, el que está presente en tanto que se despide con la promesa de su vuelta. El Jesús presente en la comunidad (quien habla a la comunidad en su aqui y ahora) es quién está siempre despidiéndose. ${ }^{87} \mathrm{Y}$ quien está siempre volviendo: "me voy y vuelvo a ustedes" (14,3.28; cf. 14,18.23 y los conocidos textos sobre el "poco de tiempo" de 16,16-19; cf. 16,22).

Los discursos de despedida de Jesús en Juan 13-17 constituyen una pieza muy peculiar de este evangelio. Sin ser totalmente ajenos a la presentación sinóptica (cf. sobre todo Lc. 22,14-38) ocupan, sin embargo, en el EJ una extensión a primera vista desmesurada y constituyen un trazo fundamental de la presentación cristológica de esta obra (hay que tener en cuenta que los discursos de despedida ocupan aproximadamente una cuarta parte del EJ).

No es necesario recordar aqui las características de este género literario tan enraizado en las tradiciones veterotestamentarias y bien presente en la literatura judía posterior ${ }^{88}$ Pero se hace necesario subrayar aqui uno de los aspectos que los caracteriza y que probablemente constituye el trazo más profundo de los mismos: el discurso de despedida es fundamentalmente un testamento espiritual. Quien se despide "deja en herencia" a sus sucesores, no una serie de bienes materiales, sino los bienes espirituales acumulados a lo largo de su vida 9 En el fondo lo que se pretende resaltar con el gesto testamentario del discurso de despedida es que quien va a morir alcanza con su testamento espiritual un cierto modo de sobrevivencia. El gesto testamentario de estos discursos apunta a la voluntad de continuar presente en los sucesores a través de la pervivencia de los valores espirituales transmitidos. Es la herencia espiritual.

Esto es,en definitiva, lo que constiluye el trazo más profundo de Juan 1317. Por encima de las exhortaciones, recomendaciones y consejos (que, como hemos de ver, incluyen como aspecto fundamental el mandamiento de amor), Jesús deja a los suyos su Espíritu (el Paráclito). Sea cual sea el momento en el cual los fragmentos sobre el Paráclito llegaron a su formulación actual (porque, como es bien sabido, muchos exegetas dirían que se trata de fragmentos muy recientes en la composición del EJ, probablemente introducidos en los niveles redaccionales del mismo), 90 resulta innegable que el contenido de la promesa del Espíritu es el meollo no sólo de estos fragmentos, sino también de los discursos de despedida. Los discursos de despedida, aunque no mencionaran la promesa del Espíritu, continuarian teniendo como contenido fundamental la sobrevivencia de Jesús a través de su Espíritu.

Este es, en último término, el sentido de la acción del Paráclito: hacer presente a Jesús entre los "suyos." De manera que la exégesis nos dice que la pre- 
sencia del Paráclito en la vida creyente coincide con la nueva presencia de Jesús. ${ }^{91}$ Por ello, en la medida que el meollo de estos discursos es la promesa del Paráclito, lo que constituye su mensaje es la explicación de la forma de presencia de Jesús en la comunidad ("me voy y vuclvo a ustedes," 14,3.28). La verosimilitud de la presencia de Jesús se explica a través de su acción y su palabra (Jesús lava los pies de los discipulos y les explica el sentido de su acción) en el nivel de su existencia terrena. La presentación plástica e "historizada" del hecho más profundo de la comunidad (la presencia de Jesús) encuentra en los discursos de despedida una forma sumamente adecuada de expresión. Sobre todo por su carácter de situación "límite," la cual confiere a la ligura de Jesús el carácter de figura también límite: quien esıá "aqui," pero se marcha, quien está "allá" pero vuelve. ${ }^{92}$

Ahora bien, es precisamente en estos capilulos, más patentemente que en el resto del evangelio, donde Jesús es quien ha dejado tras de si "la obra," quien ha cumplido el mandamiento y ha sido exaltado. Jesús es presentado aqui como quien se va, pero en la medida en que ha vuelto y habla a los suyos. La misma forma como Jesús habla en estos capítulos muestra a las claras que él es al mismo tiempo quien se ha marchado: "estas cosas se las dije mientras estaba con ustedes" $(14,25)$; "todo esto lo dije desde el comienzo, porque estaba con ustedes" $(16,4 b)$, etc. Pero hay una fórmula que se repite una y otra vez a lo largo de estos discursos y que muestra el carácter de interpelación directa de la palabra de Jesús, la cual es sobre todo actual: "les he dicho estas cosas..." $(15,11.17 ; 16,1.4 a .33 ; 17,13 ; \mathrm{cf} .14,25.29 ; 16,6.25)$. Muchos de esios

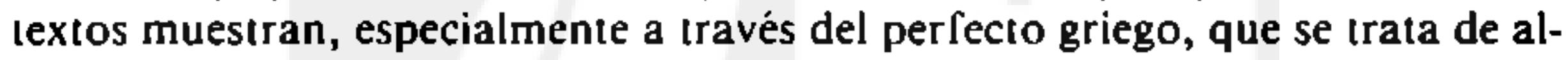
go que Jesús dice y que continúa teniendo vigencia, continúa siendo válido y actual para el lector. Y en la medida en que el Jesús que se despide de los suyos es el Jesús que ha vuelıo y está presente en la comunidad, esta comunidad lee los textos de estos discursos en profunda sintonía con el "ustedes" a que se refiere Jesús.

Por tanto, una lectura del EJ que quisiera mantener la distancia entre los discípulos de Jesús, oyentes de su despedida, y los lectores del evangelio, perdería este carácter de interpelación directa, el cual puede percibirse en el texto y constituye una de las características más profundas del EJ. Los discursos de despedida exigen de los creyentes joánicos separarse del mundo para escuchar al Señor que se despide. Por eso el lector no acaba de saber si hay diferencia alguna enıre los discipulos quienes escuchaban la despedida de Jesús y él mismo. Lo que si sabe, porque lo confiesa, es que el mismo Jesús le está dirigiendo la palabra y le está explicando el sentido de su actuación en el mundo.93

\subsection{Jesús en la comunidad joánica}

Hay otro aspecto muy importante en la presentación cristológica de los discursos de despedida, el cual retoma y profundiza lo dicho hasta aqui. La comunidad que escucha a Jesús en estos fragmentos sabe que el contenido fundamental de la despedida de Jesús es el Paráclito. Con la acogida del Paráclito se está realizando en la comunidad el testamento espiritual de Jesús. Por lo tanto, 
con la acogida del Paráclito, la comunidad pasa a vivir la vida bajo la inspiración del Espíritu de Jesús. En una palabra, la comunidad pasa a vivir la misma vida de Jesús.

Esto ha quedado indicado antes cuando hemos explicitado que la labor del Paráclito es fundamentalmente "hacer recordar" a la comunidad lo que Jesús hizo y dijo (14,26; cf. 16,13 y los texlos del "recuerdo:" 2,22: 12,16: cᄃ. 20,9). La comunidad joánica vive de esta manera la vida de Jesús, porque el contenido fundamental de la realidad del Paráclito es precisamente esta vida de Jesús ofrecida y entregada por los suyos. Este es el contenido del llamado "mandamiento del amor." Veámoslo. ${ }^{94}$

La relación entre Jesús y los suyos está marcada por el tema del amor de Jesús a los suyos y ia entrega de su vida por aquellos a quienes ama $(13,36$; 15,13 y 10,17-18). Pero el amor y la entrega de Jesús no son originales: "como el Padre me ha amado, también yo los he amado" $(15,9)$. El amor (la donación) ${ }^{95}$ de Jesús no ha comenzado en él. Más aún, la expresión "como el Padre me ha amado" tiene una fuerte connotación causal: no significa sólo "de la misma manera que el Padre me ha amado," sino también y sobre todo "porque el Padre me ha amado." 96 Jesús no sólo ama a los suyos con el mismo amor que el Padre lo ha amado a él, sino que además Jesús puede amar precisamente porque el Padre lo ama.

Conviene recordar que según Jesús el "hijo no puede hacer nada sin el Padre" y que todo lo que hace y dice, lo hace y lo dice porque ve al Padre haciéndolo $(5,19.30)$, o escucha al Padre que le habla $(8,28 ; 8,40 ; 12,49-50)$. En el fondo, por lo tanto, el hijo puede amar (entregar su vida: $15,13:$ cf. 3,$34 ; 13,3$ ) porque el Padre lo ama (se lo da todo, se le entrega: le da el tener vida, 5,26, y poder disponer de esta vida, 10,17-18). Por consiguiente, el amor de Jesús es posible porque existe el amor del Padre. La donación de Jesús a los hombres se da como prolongación del don del Padre a Jesús. Por eso el amor de Jesús (la entrega de Jesús) incluye, como primer paso indispensable, el amor del Padre a Jesús (la entrega del Padre al hijo). En consecuencia, cuando hablamos del amor de Jesús, hemos de tener presente que este amar de Jesús tiene un primer momento indispensable y constitutivo: el Padre ama a Jesús y, por lo tanto, Jesús vive su vida en la fuerza y la confianza que le confiere el haberla recibido. Hablando más antropológicamente, Jesús vive la vida como un don y, en la medida que vive la vida como un don, puede dar esta vida a los hombres.

En el EJ el paralelo entre Jesús y el creyente es prácticamente perfecto. Por esto, de la misma manera que Jesús vive su vida en constante actitud de fidelidad plena al Padre (de fidelidad al mandamiento recibido del Padre y de fidelidad a la voluntad del Padre: 4,$34 ; 5,30 ; 6,38 ; 10,17-18 ; 12,49-50 ; 14,31$; 15,9-10), asi también el creyente recibe el mandamiento de Jesús: amar como el mismo Jesús $(13,34-35 ; 15,12 ; 15,17 ;$ cf. $1 \mathrm{Jn} .3,23)$. Muy a menudo damos a esta expresión "como Jesús" la fuerza del ejemplo: es como una exhortación a reproducir en la vida del creyente la manera concreta como Jesús ha vivido. Pero la rórmula, sin excluir en manera alguna este sentido, va mucho más lejos. También aquí la expresión "tal como Jesús" tiene fuerza causal: la misma 
que encontrábamos antes en la relación entre Jesús y el Padre. Precisamente por ello, a fin de que el amor de Jesús actúe en el creyente, éste ha de acoger este amor, ha de dar cabida en su vida al amor de Jesús.

De esta forma la vida de Jesús no es sólo un punto de referencia ejemplar $(13,15)$. La vida y la muerte de Jesús (y muerte significa aquí “dar la vida por aquellos a quienes se ama" 15,13) lo incluye todo: las palabras, las obras, la doctrina, y la enseñanza de Jesús. El creyente al ser exhortado en el EJ a acoger las palabras $(8,31)$, la enseñanza $(12,49-50 \mathrm{cf} .7,17)$ y la doctrina de Jesús, es exhortado a acoger su vida y su muerte. Es decir, es exhortado a acoger el amor de Jesús. Y dicho teológicamente, es exhortado a acoger el Espíritu Santo. Con ello la acogida del Paráclito es la acogida de la vida de Jesús. Una vida que el evangelio se ha encargado de formular a nivel de tesis: la vida del hombre llamado Jesús, del hijo de José.97

Es la aceptación de la donación de la vida de Jesús lo que capacita al creyente a dos cosas: para vivir la vida como un don y para dar su vida (cf. $1 \mathrm{Jn}$. 3,16). Tal como decíamos al hablar de la relación entre Jesús y el Padre: el amor de Jesús a los hombres no es sólo modelo, sino que es sobre todo parte del amor del cristiano. Es el primer paso de este amor, porque es el contenido del amor del cristiano: sin el amor de Jesús acogido, el amor cristiano es imposible. El cristiano puede amar porque Jesús lo ama. Puede vivir porque Jesús le da la vida. Y entonces la vida del cristiano es la vida de Jesús (como la vida de Jesús es la misma vida del Padre). ${ }^{98}$

Por consiguiente, en el EJ la vida cristiana se define esencialmente por la aceptación del amor de Jesús (de su vida). Sólo si se acepta la donación de Jesús es posible vivir la vida como un don y, en consecuencia, dar la vida. Pero el primer paso de esta cadena es indispensable y constitutivo del creyente en cuanto creyente. $Y$ es precisamente este primer paso el que engendra la confianza con la cual el creyente puede vivir y dar la vida. Es este primer paso el que justifica usar la terminologia del "creer," la cual, en definitiva, es la terminología que expresa la confianza. Este primer paso (la aceptación de la donación de la vida por parte de Jesús) es lo que el EJ llama "creer" y es lo que lleva al hombre a la vida en plenitud: "el que cree ha pasado de la muerte a la vida" $(5,24)$.

A la luz de esta concatenación Padre-Jesús-comunidad, en el EJ asistimos a una verdadera implementación del testamento de Jesús a través de la labor del Paráclito en la vida creyente. ${ }^{99}$ Es el Paráclito quien pone en marcha la existencia cristiana como existencia de Jesús. La vida de la comunidad joánica encuentra en la vida de Jesús la profundidad de la propia vida. Y a la luz del Paráclito (quien hace recordar y enseña el sentido de la vida de Jesús) se descubre en los gestos y palabras de Jesús $(2,22 ; 12,16)$ el sentido de la propia existencia.

Por ello la comunidad joánica relee la vida de Jesús como una profunda alegoria de su propia vida. Es el mismo Jesús quien está presente en la vida de la comunidad. Aqui está, en último término, la razón de ser más profunda de lo que se llama el carácter simbólico del EJ. Se trata de un simbolismo 
intrinseco ${ }^{100} \mathrm{El}$ Jesús presente es aquél que, al despedirse, deja como herencia a la comunidad todos los bienes espirituales acumulados a lo largo de su vida. Es toda la vida de Jesús lo que resulla aquí un "bien" acumulado. El Paráclito, en su labor de traer a la memoria los gestos y las palabras de Jesús, no hace otra cosa que implementar su testamento. Con ello, la vida terrena de Jesús se hace profundamentc simbólica al estar extraordinariamente presente.

\section{Conclusión}

El hilo conductor de nuestra presentación ha sido la cuestión sobre la realidad del Jesús terreno en el EJ. Y más en concreto hemos intcntado iluminar a lo largo de la misma el sentido y papel de la vida de Jesús tanto en la reflexión cristológica comunitaria como en la misma estructura del EJ.

De lo dicho podemos concluir que la vida de Jesús. la realidad del Jesús terreno, es un aspecto esencial de la presentación cristológica hecha por la comunidad en el EJ. Estamos ante un aspecto tan esencial de la confesión cristológica joánica, un aspecto tan intimamente integrado en la misma, que dificilmente se puede pasar por alıo. Si lo consideramos una añadidura extrínseca (como si se iratara de relazos de una tradición prácticamente olvidada o de un intento de hacer ortodoxa una cristología abocada al docelismo), entonces, simplemente, no podría ser verdad que la comunidad haya podido contemplar la gloria precisamente en la vida terrena de Jesús ("si crees verás la gloria de Dios," 11,40 ) y que la haya podido contemplar aqui y ahora en la vida de la comunidad ("hemos contemplado su gloria," 1,14). Y si la ignoramos o la pasamos por alıo, entonces resulta que nos quedamos sin el meollo doctrinal de la obra, nos quedamos sin el contenido fundamental de la confesión ("... tú, siencio hombre, te haces a li mismo Dios," 10,33; "El Logos se hizo carne (hombie)," 1,14).

Destaquemos dos vertientes en las cuales el presente trabajo puede contrihuir a una mayor profundidad de la reflexión cristiana.

\subsection{La interpretación del FJ}

A la luz de nuestra presentación, el EJ aparece ante el lector como una gran confesión de le de la comunidad joánica. Esıo no sólo caracteriza a esta obra sino que, además, le confiere un profundo carácter de obra doxológica que conviene leer también doxológicamente. Porque lo que pretende el EJ es no sólo verbalizar la fe de la comunidad, sino hacerlo de forma que cl lector pueda adherirse al Jesús confcsado. Por ello, Jo que tenemos en el EJ es la Homologia de la presencia actuante de Jesús de Nazaret en el seno de la comunidad. Una presencia justificada teológicamente con la figura del Paráclito. Pero tambièn una presencia que no pondrá el acento en los gestos concretos ni en las palabras pronunciadas por Jesús. Al Iralarse clè una confesión de le, la realidad de la vida terrena de Jesús es presentada sobre todo con los trazos de la globalidad: es presentada a nivel de tesis. Así hemos podido apreciar que la forma concrela de "decir" la humanidad de Jesús en el EJ es la que correspon- 
de al lalante doctrinal de las confesiones de esta comunidad: "este hombre es el hijo de Dios" $(19,5.7$; cf. 8,40 y 10,33), "este hombre es el salvador del mundo" $(4,42)$. Es de esta Torma y no de otra como los gestos y las palabras de Jesús, su vida y su muerte constiluyen un aspecto absolutamente inseparable del objeto de la fe y de la confesión comunitarias.

Entonces parece claro que la vida de Jesús (la historia de Jesús, en una rormulación más solemne) 101 entra en la exposición y presentación de la fe de esta comunidad, no como un marco general en el cual se inscribe el hecho salvífico, no como fruro de una valoración intrínseca de la tradición ni tampoco, linalmente, del posible influjo de alguno de los evangelios sinópticos. La vida de Jesús es una catcgoría esencial de la confesión cristológica joánica en la medida que es fruto de la experiencia cristológica de la comunidad. Se trata de una categoría alcanzada desde dentro, desde la experiencia creyente de la comunidad. Esto es importante y hay que explicitarlo brevemente. ${ }^{102}$

En la comunidad joánica no es desde la pretendida validez de la "historia" como dato primero e intocable como vamos a parar a la presentación de la vida de Jesús, nccesaria para la re. Lo que queremos decir se muestra más fácilmente apelando a la concepción del tiempo y de la historia en esta comunidad: lo decisivo aqui no es la historia en si misma. Lo que hace decisiva la vida de Jesús es que se trata precisamente de la vida de este Jesús confesado y, por lo tanto, presente. Es a la luz de esıa confesión que sus gestos y sus palabras, su vida y su muerte adquieren un valor definitivo. Un valor que no lenian en sí mismos.

Tampoco la tradición "histórica" de la comunidad lleva necesariamente a la presentación cristológica que tenemos en el EJ. En primer lugar, porque la tradición sobre Jcsús estaba abierta a múltiples interpretaciones y sentidos, tal como lo muestran no sólo los evangelios sinópticos, sino también otros documentos neotestamentarios. Pcro, además, si apelamos a la progresiva elabora(iion del EJ, llegaremos a la misma conclusión. Si, como parece probable, la comunidad joánica elaboró primero un "mini-evangelio" que contenia fundamentalmente material narrativo, el cual fue ampliando poco a poco (sobre to(lo a través de diálogos y controversias, en un ambiente catequético y misionero) hasta alcanzar la forna actual, sin embargo, el "genio" de la presentación joánica sólo alcanzó su madurez cuando la presentación cristológica de la mismia comunidad se estrucluró en torno a la experiencia del Paráclito. Por lo tanto, lo decisivo en la tradición joánica no son los daros tradicionales sobre gestos y palabras de Jesús. Lo decisivo para la forma "cvangélica" de la presentación joánica es la te cristológica de la somunidad.

Finalmente, tampoco se debe la valoración de la vida de Jesús de la comunidad joánica a un mimnetismo extrinseco que hubiera conocido y "copiado" la estructura de alguno de los evangelios sinópticos. En primer lugar, porque no parece que pueda detectarse influjo alguno de los sinópticos en el EJ. Pero, col último término, porque la estructura "evangélica" del E.I se debe a la importancia y profundidad de la fe y de la confesión. Más aún y de un modo especial, el objeto de la fe y de la confesión comunitaria es más importante que la inisma experiencia del Paráclito que (iene la comunidad. Si bien es verdad 
que la comunidad joánica acoge al Paráclito y, por lo tanto, experimenta su presencia, sin embargo, el contenido de esta experiencia espiritual es Jesús: el Jesús total y, por consiguiene, también el Jesús terreno. Lo que se percibe en la experiencia del Paráclito tiene un peso específico mayor que el mismo Paráclito. ${ }^{108}$ Es aquí donde alcanza su dimensión plena la presentación de Jesús como quien es al mismo tiempo el pre-existente, el terreno y el exaltado, porque ésto es, en definitiva, el Jesús presente en la comunidad, es decir, el confesado por ella.

El "genio" de la presentación joánica no viene, por lo tanto, ni de un genérico concepto de "historia," ni de la peculiaridad de la tradición ni del (en cualquier caso sólo posible) influjo de los sinópticos. Viene más bien de la necesaria recuperación de los datos centrales de la vida de Jesús, hecha a la luz de la experiencia creyente de esta comunidad: la presencia de Jesús que se impone como recuerdo del mismo Jesús $(14,26)$, pero no un recuerdo detallista y anecdótico. La comunidad joánica hace una selección de gestos y palabras para ilustrar el contenido de la confesión. Es, en úlıimo término, la peculiar experiencia cristiana de la comunidad joánica lo que se expresa en lo que llamamos el EJ. Por ello, si lo que quería justificar este grupo era la posibilidad de la fe para los lectores $(20,30-31)$, tenia que escribir precisamente "este" evangelio, ${ }^{104}$ pues se trataba de posibilitar a los lectores la misma fe que se habia experimentado. Y, por lo tanto, era imposible hacerlo de otra forma: había que presentar el núcleo cristológico de la fe y de la experiencia joánica de forma que pudieran ser acogidos y asimilados. 105

\subsection{EJ EJ y la reflexión sobre la vida de Jesús}

Si lo que hemos expuesto apunta en la dirección correcta, entonces este trabajo ha de contribuir también (aunque sea de forma muy básica e incipiente) a una integración del EJ en la reflexión cristológica contemporánea sobre la vida de Jesús. Por lo menos en la medida en que ha de disipar la incomodidad que hemos mencionado en la introducción.

Pero nuestro aporte quiere ir más lejos. Esta integración del EJ en la reflexión sobre la vida de Jesús debería contribuir a profundizar y enriquecer nuestra reflexión cristológica, porque la recuperación de la vida de Jesús en la comunidad joánica se hace al margen (aunque no directamente en contra) de un esquema teológico de historia salutis, el cual tiene sus representantes bien patentes en el Nuevo Testamento (por ejemplo, Lucas y también Pablo). Pero no es el único esquema utilizado. Tanto la cristología de la carta a los Hebreos 106 como la que hemos expuesto en estas páginas ofrecen un esquema de recuperación de Jesús bien profundo y sugerente, el cual no utiliza el marco de la historia salutis como molde teológico. Por consiguiente, la cuestión de la vida de Jesús en el Nuevo Testamento no es una cuestión univoca. No todos los autores neotestamentarios se la han planteado de la misma forma. Y, por lo tanto, con nuestro aporte, es la cuestión misma de la vida de Jesús la que résulta iluminada, e indirectamente resulta ampliada y enriquecida. La historia de Jesús no es importante porque cualquier momento histórico lo es en si mismo. Es Jesús quien ha hecho imborrable un momento determinado de la historia. ${ }^{107}$ 
Por ello estas páginas más que ser una contribución directa a la reflexión cristológica latinoamericana quisieran of recer una posible ampliación y enriquecimiento. La comunidad joánica es un ejemplo patente de cómo la vida de Jesús crea historia (Jon Sobrino), una historia que, a pesar de la amenaza y la persecución (Jn. 15,18-16,4a) continúa siendo la historia de Jesús. $O$ tal vez lo es precisamente porque está amenazada y perseguida: "si me persiguieron a mí, también a ustedes los van a perseguir" (Jn. 15,20). El EJ ha historizado la vida de Jesús, pero lo ha hecho sobre todo en la historia de la comunidad.

\section{Apéndice: la vida de Jesús en 1Jn.}

La relación entre el EJ y las cartas joánicas es un dato perenne de la exégesis neotestamentaria. Pero, además, es un aspecto que ha adquirido gran actualidad en estos últimos años. ${ }^{108}$ Dado que se considera que las cartas joánicas son escritos posteriores al EJ puede ser interesante preguntarse cómo se valora en estos escritos (fundamentalmente en la IJn.) la vida de Jesús. Y resulta interesante porque estamos ante un escrito de la misma comunidad, pero que no presenta en absoluto la forma narrativa tan peculiar en el EJ. Y, por lo tanto, si en la primera de Juan hay una valoración distinta de la vida de Jesús para la fe comunitaria, habremos encontrado una confirmación bien relevante de lo que hemos dicho en nuestro estudio.

No vamos a tratar el tema en toda su amplitud por razones obvias. ${ }^{109} \mathrm{Li}$ mitaremos nuestra breve indagación a tres puntos.

\section{Sentido de las confesiones en $1 \mathrm{Jn}$.}

Dada la centralidad de Jesús en este breve escrito y dada la sorprendente frecuencia con que se refiere a Jesús, 110 resulta significativo indagar el acento fundamental de las confesiones de fe que presenta:

- “¿quién es el mentiroso sino el que niega que Jesús es el Mesias?" $(2,22)$;

- "quien confiesa que Jesús es el hijo de Dios..." $(4,15)$;

- "todo aquel que cree que Jesús es el Mesias..." $(5,1)$;

- "¿quién vence al mundo, sino el que cree que Jesús es el hijo de Dios?" $(5,5)$.

Notemos, en primer lugar, que el sujeto de estas confesiones es siempre "Jesús," con esta denominación tan sencilla pero también tan en fática. ¿Dónde está el acento de estas homologias? Si en las confesiones tradicionales del Nuevo Testamento tenemos el acento en el predicado, en la primera de Juan, este acento ha sido desplazado. Lo que se subraya en estas fórmulas no es que Jesús sea el Mesias o el hijo de Dios, sino al revés,que es precisamente Jesús quièn lo es. ${ }^{111}$ Esto se hace patente tanto en la diversidad de predicados como sobre todo en las frases aclarativas añadidas al sujeto de las confesiones: "todo espiritu que confiesa a Jesucristo venido en la carne es de Dios" $(4,2)$; "él, Jesucristo, ha venido por el agua y la sangre, no solamente en agua, sino en 
agua y sangre" (5,6, cf. "muchos embaucadores han aparecido, los que no confiesan a Jesús Mesías venido en la carne," $2 \mathrm{Jn}$.7). El acento de estas fórmulas está, por lo tanto, en el sujeto y, recordémoslo, el sujeto es siempre Jesús.

\section{El carácter no doctrinal de la fe en $\mathbf{1 J n}$.}

El uso del verbo creer en la primera de Juan está en plena continuidad con el evangelio: tiene siempre como objeto a Jesús. ${ }^{113}$ Por lo tanto, apunta más a una persona que a una doctrina. Pero, además, un análisis muy somero de la fe como fides qua en la carta nos lleva a la conclusión de que "creer" es, por encima de todo, realizar obras $(3,17 ; c\lceil .1,6$, y también Jn. 3,20-21; 6,28-29). "Creer" implica una confesión no meramente verbal, porque coincide en realidad con la praxis del mandamiento del amor $y$, por consiguiente, no es tan doctrinal como pueden hacer suponer las confesiones ciladas más arriba.

Es bien sabido que de la primera de Juan se pueden entresacar las afirmaciones de los adversarios, porque éstas han sido introducidas en fórmulas fijas, las cuales se van repitiendo a lo largo del escrito. 14 Pues bien, todas las contraposiciones a las afirmaciones de los adversarios se reducen a echarles en cara que no aman: dicen que tienen comunión con Dios, pero de hecho caminan en las tinieblas (es decir, no aman: 1,6 ; cf. 2,9.11); dicen que no tienen pecado, pero en realidad pecan (es decir, odian: $1,8.10$ y 3,4.8.15); dicen que conocen a Dios, pero no guardan su mandamiento (que es el mandamiento de amar; 2,4-5); dicen que están en él, pero no se comportan como él (es decir, no aman como Jesús: 2,$6 ; \mathrm{cf} .3,12-16$ ); dicen que están en la luz, pero odian a los hermanos $(2,9)$; dicen que aman a Dios, pero no aman a los hermanos $(4,20$ 21). Toda la doctrina de los adversarios encuentra únicamente clara y definida contraposición en la primera de Juan: amar. No hay otro principio para conformar y estructurar la vida cristiana.

Además, lo conocido de estas confesiones es "Jesús" más que los títulos. La familiaridad con que la comunidad joánica habla de Jesús en la primera de Juan se hace especialmente patente en el uso del "nombre," pero también al referirse a Jesús como aquél (ekeinos) de forma clara e inequivoca. ${ }^{114}$ En cambio, los títulos (Mesias, hijo de Dios) podian evocar figuras entrevistas y esperadas. Pero lo que subraya el texto es que se han realizado precisamente en Jesús. Por ello, la figura de Jesús no es un mesias genérico, no un hijo de Dios sin concreción. Es el venido en la carne, quien ha muerto por los pecados de los hombres. Y si es intercesor junto al Padre $(2,1)$, lo es precisamente mediante su sangre $(1,7 ; 6,6.8)$. Jesús tiene siempre las señales de la cruz y de la sangre como medio de identificación $(2,2 ; 4,10 ;$ cf. 3,16$)$.

La continuidad de la primera de Juan con el evangelio es muy clara y nítida. Si bien en las con Tesiones de la carta percibimos las connotaciones de una polémica abierta con los adversarios $(1 \mathrm{Jn} .2,19)$, los acentos cristológicos no recalcan algo distinto de lo que hemos encontrado en el EJ. Lo interesante es que el acento en la realidad humana de Jesús en la primera de Juan se hace en una forma no narrativa. Esto podría dar la impresión de que estamos ante una concepción más doctrinal de la confesión y de la fe. Pero no es éste el caso. 
Nada de esto es nuevo. El EJ en los discursos de despedida no sólo explicita que el mandamiento del amor es la única directriz dada al creyente joánico para su actuación, sino que, además, lo formula diciendo: "en esto conocerán que ustedes son mis discípulos, si se aman unos a otros" (Jn. 13,36). En este texto incluso la fórmula "en esto conocerán..." resulta bien cercana de las formulaciones de la carta. ${ }^{11 s}$

Por otro lado, este carácter no doctrinal de la fe, en tanto que fides qua, en la primera de Juan se confirma con un último punto que recoge más profundamente su continuidad respecto del EJ.

\section{El papel de los "hechos de Jesús" en la fe}

También en la primera de Juan, como en el evangelio, la figura de Jesús es presentada como la clave de la vida creyente. Esto queda bien patente en las exhortaciones que, a primera vista, presentan a Jesús como modelo a imitar. En la carta encontramos la misma formulación que hemos encontrado en el cvangelio: "de la misma manera que..." Recordemos los textos de la carta:

- "el que dice que está en él ha de comportarse de la misma manera que aquél se comporló" $(2,6)$;

- "así, tal como les enseñó, perseveren en èl" $(2,27 ;$ cf. 3,23$)$;

- "y el que tiene esla esperanza en él se purifica, tal como él es puro" $(3,3)$;

- "el que practica la justicia es justo, de la misma manera que él es jus10" $(3,7)$;

- “... porque de la misma manera que èl está en el mundo, nosotros también estamos en el mundo" $(4,17)$.

La expresión "de la misma manera que" (kasthoôs) tiene en estos textos, como en el EJ, la fuerza de fundamento, liene fuerza causal. Por eso se propone al creyente la acogida de los "hechos" de Jesús como fundamento de su vida. Asi lo manifiesıa el llamado prólogo (1Jn, 1,1-5), la mención de la praxis de Jesús $(2,6)$ y la exhortación a dar la vida, porque Jesús mismo donó su vida $(3,16)$. Lo que reivindican estos puntos de referencia son los hechos de Jesús: "aquello que hemos visto, aquello que hemos contemplado, aquello que nuestras manos han palpado... esto es lo que les anunciamos" (1,1-3). El anuncio, lo que hay que acoger y aquello donde hay que permanecer, son, en definitiva, unos hechos. La fórmula "aquello que..." asi lo indica: tanto en su carácter complexivo (se trata de "algo" que puede verse, escucharse, tocarse), como sobre todo en el acento en que "aquello" se ha hecho patente, se ha manifestado. Porque no hay anuncio sin "algo" que ha sido contemplado, visto... Es la phanerôsis de Jesús lo que se anuncia. Es, por lo tanto, su vida terrena. ${ }^{116}$

Es aqui donde hay que situar el sentido del "de la misma manera que." Entonces la confesión comunitaria dirá sin ambages que "nosotros amamos porque él nos ha amado primero" (1 Jn. 4,$19 ; \mathrm{cf} .2,6-7 ; 2,27 ; 3,23 .$. ). La vida creyente se ha puesto en marcha por la donación de la vida de Jesús $(3,16)$ y por la acogida (creer) y la confesión del creyente. Más aún, la existencia de Je- 
sús y la donación de su vida son la médula de la identidad del cristiano. El contenido esencial de la vida cristiana es, en este sentido, Jesús, "porque, tal como él es en el mundo, de la misma manera somos nosolros en el mundo" ( $1 \mathrm{Jn}$. 4,$17 ;$ cf. 2,8, y también "porque el está en ustedes es mayor que el que está en el mundo," 4,4).

En este contexto cristológico, el creer del cristiano en cuanto fides quae creditur no corresponde directamente a un enunciado verbal ("no creamos con la palabra o con la boca, sino con obras que son fruto de la verdad," 3,17 ). Aquí creer es más bien un dejarse conformar según Jesús, es hacer de Jesús el centro de la vida creyente. Por lo tanto, estamos ante una realidad más teologal que doctrinaria, como lo muestra el hecho de que el punto de partida de la confesión es "que nos ha dado de su Espiritu" ( $1 \mathrm{Jn}$. 3,24; 4,13 y el tema de la unción en 2,20.27). También amar en la carta ( $y$ en el evangelio) es una realidad más que un principio de moral. La fórmula que mejor resume nuestro breve argumento se encuentra en una compendiosa enunciación del mandamiento: "este es su mandamiento: que creamos en el nombre de su hijo Jesucristo y que nos amemos los unos a los otros como nos mandó" $(3,23)$.

Por consiguiente, que Jesús sea la vida del creyente quiere decir esto, si Dios entra en la vida del hombre por medio de Jesús (en el don del Espíritu), todo queda penetrado de su presencia. De esta forma, lo que llamamos doctrina pasa a ser "vida en la presencia de Dios." Así la doctrina es más la experiencia teologal que un enunciado dogmático. En una palabra, la distinción entre doctrina y vida deja de ser relevante. La doctrina es, en realidad, la persona acogida (Jesús presente) y lleva a vivir "de la misma manera" que este Jesús, porque, en definitiva, se vive por Jesús (1Jn. 4,9; cf. Jn. 6,57).

$$
++++
$$

Nuestro interés en este breve apéndice no era tanto trazar una linea de continuidad entre el EJ y la primera carta de Juan (aunque esto queda necesariamente implicado) cuanto recalcar que el interés por la vida de Jesús que hemos encontrado en el EJ subsiste en la carta. Sin embargo, se expresa con módulos literarios bien diversos. Queda asi más claramente ilustrada la hipótesis que ha constituido nuestro punto de partida: en el Nuevo Testamento el interés por la vida terrena de Jesús, por su historia, se expresa de modos bien diversos, y en este sentido los evangelios sinópticos no constituyen un criterio exclusivo de recuperación de la historia de Jesús.

\section{NOTAS}

I. El reciente documento de la Pontificia Comisión Biblica asi lo reconoce, cuando en la sección 2 de la segunda parte comienza la expusición de la "cristologia total" con los datos sobre la misión de Jesús y habla de la persona de Jesús como "origen de la cristologia." Puede verse el texto en J. Fitzmyer. "The Biblical Comission and Christology," Theological Siudies 46 (I985) 407-459, más en concrelo pp. 435-438 y cl comeniario de Fitzmyer en pp. 477-478.

2. "Recuperar la humanidad de Jesús," asi tiulaba J. Vives la presentación del libro de J.J. González Faus, Acceso a Jesús, (Salamanca, 1979). cf. Revisia Española de Teologia 38 (1978) 385-396 (el volumen de esta revista, a pesar de llevar fecha de 1978, apareció en 1980). 
3. Hablando en terminos muy generales podemos decir que estos últimos años han visto la aparición de obras cristológicas de talante bien diverso, pero que comparten este interćs por Jesús y su historia. El documento citado en la nola 1 es una clara muestra de ello. Pero conviene citar algunos nombres bien conocidos para substanciar nuestra afirmación: ell centroEuropa podriamos mencionar las cristologias de J. Moltmann, W.Pannenberg, Ch. Doquoc, W. Kasper y E. Schillebeeckx; en España a X. Pikaza y J.I. González. Faus; en América Latina a L. Boff, J. Sobrino y J.L. Segundo; a estos grupos hay que añadir la incisiva obra del leólogo japonés K. Kilamori, Teología del dolor de Dios, Salamanca, 1975 (hay que tener en cuenta que el original de esta obra data de 1958), la cristologia del teólogo indio S. Kappen (Jesús and Freedom, New York, 1977) y la relexión sobre la vida de Jesús en Sudáfrica a cargo de A. Nolan (Quien es este hombre. Jesuis antes del cristianismo, Santander, 1981). Evidentemente, esta nota quiere ser sólo indicativa.

4. Esto resulta tan conocido que no es necesario detallarlo más. Puede verse un resumen en cualquier introducción al EJ. Por ejemplo, R. Schnackenburg. El Evangelio seguin San Juan. Version y comentario, tomo I, Barcelona, 1980, pp. 44-73 y más en detalle pp. 56-71.

5. Por ejemplo, cuando se trata de alargar el ministerio de Jesús a un perlodo de tres años, en vez. del año que encontramos en la presentación sinóplica (sobre todo en Lc., ef. Lc. 4,19).

6. Es decir, se toman los datos cronológicos y geográficos de Juan como si tuvieran el mismo sentido que en los sinópticos. $O$, lo que es lo mismo, como si todos estos datos pudieran ser catalogados como mera "in formación histórica." Véase lo que decimos más adelante en este sentido.

7. No sólo porque el EJ presenta, profundizándola, la relación de Jesús con el Padre (cГ. el Abba sinóptico), sino sobre todo por las Tormulaciones joánicas ("yo y el Padre somos una misma cosa," 10,30; "cl Padre es mayor que yo," 14,28; "quien me ha visto a mi, ha visto al Padrc," 14,9: cf. 12,45, cıc.) que han sido ampliamente utilizados a lo largo de la historia de la cristologia.

8. Como lo muestra el hecho de que el EJ es un verdadero campo de batalla en las discusiones cristologicas patristicas de los siglos IV y V: F.M. Braun, Jean le Théologien, vol. I, Paris, 1959 (cf. en cambio J.N. Sanders, The Fourth Gospel in the early Church, Cambridge, 1943); M.F. Wiles, The Spirimal Gospet. The interpretation of the Fourth Gospel in the early Church, Cambridge, 1960; T.E. Pollard, Johannine Christology and the early Church, Cambridge, 1970. No deja de ser relevante recordar el amplio uso del EJ en círculos gnósticos y montanistas (cf. E.H. Pagels, The Johannine Gospel in Gnostic Exegesis, Nashville, 1973).

9. En definitiva, el sentido de las afirmaciones cristológicas del EJ sólo puede ser comprendido en el contexto del mensaje del mismo y no como formulaciones más o menos ortodoxas, por mucho que la Iradición pairistica las haya usado. Conviene recordar aqui, porque se trata de un principio hermenéutico de gran Iranscendencia, que lo que el canon ha sancionado como inspirados son los libros, y no el sentido que la tradición patristica dio a fragmentos determinados de las obras biblicas.

10. Esta paradoja constiluye un verdadero lópico de la interpretación del EJ: sorprende la minuciosidad y aparente exactitud informativa del mismo. Pero este rasgo no acaba de casar con la profundidad teológica de su cristologia. Y, sin embargo, se continúa utilizando el EJ en dos niveles bien distintos, sin integrarlos.

11. Lo que se dice en este párrafo se debería justificar más de cerca, pero aqui no es rosible; puede verse la obra ya clásica de W.F. Howard, The Fourth Gospel in recent Criticism and Interpretotion, edición revisada por C.K. Barrett, London, $4_{1955}$ y el trabajo de Ph.H. Mtnoud, "Les études johannqiues de Bultmann à Barrett" publicado en L'évangile de Jean, Brugges, 1958, pp. 11-40.

12. Vèase la panoramica de J.A.T. Robinson, "The 'New Look' on the Fourth Gospel," publicado primero en Studia Evangelica I, Berlin, 1959, y reproducido en su obra Twelve New Tesiament Studies, London, 1962, pp. 94-106 y lambièn el balance de A.M. Hunter, According ro John, London, 1968. Un bolelín bibliográfico de esta época lo publiquè en 1974: 'El cuarlo evangelio: balance de un decenio (1964-1973), "en Actualidad bibliogrdfica 11 (1974) 243-289.

13. La Tradicion his/orica en el cuarto Evangelio, Madrid, 1978 (original de 1963).

14. R.E. Brown en su recensión de la obra de Dodd en Theological Studies 25 (1964) 431: Perhaps this reviewer is prejudiced because D's view is close to his own, but in its broad outlines D's solution seems to be definitive. 
15. O, para decirlo con mayor exaclitud, centrado en el valor de la información histórica del EJ. Porque la cuestion del autor ocupó en estos años una importante parcela de los estudios joánicos. Véase "El cuarto evangelio: balance." citado supra en la nota 12, pp. 255-257; 259261.

16. Justificar esta valoración resulta aquí imposible. Puede verse J.O. Tuñi, "La investigación joánica en el decenio 1974-1983" publicado en Actualidad Bibliogrófica 21 (1984) 36-81, sobre todo pp. 47-67.

17. No deja de ser significativo en este sentido que varias obras publicadas en estos años y que usan en el tilulo la palabra "historia," tratan de la "historia" de la comunidad en Juan, no de la "historia" de Jesús, cf. por ejemplo J.L. Martyn, History and Theology in the Fourth Gospel, New York, 1968 (2 1979); F. Vouga, Le Cadre historique el l'intention theologique de Jean, Paris, 1977.

18. En este sentido escribiamos en 1974: "No deja de ser significalivo que $R$. Schnackenburg, en la vasta inıroducción a su comentario, no le dedica (al tema de la hisıoricidad) más que un párrafo, en el que se limita a hablar de 'informaciones suplementarias (a los sinópticos) que merecen atención.' La inıroducción al comentario de R.E. Brown tiene tres páginas sobre el valor de la información hisıórica del cuarıo evangelio... En realidad R.E. Brown no hace más que escudarse por una parte en su firme convicción del valor histórico de la sólida tradición jónica... y por otra en su hipotética reconstrucción de cinco estadios en la formación del evangelio... " "El cuarto evangelio: balance," citado en la r1ula 12, pp. 255-256. A esta apreciación podríamos añadir que en oiro boletín, publicado en 1984 (cf. supra, nota.16) y dentro de 114 títulos de libros sobre los escritos joánicos, no hay ni un solo titulo que haga referencia al tema de la historicidad. Lo cual es, por lo menos, altamente significativo.

19. Normalmente la exégesis se ha referido a este aspecio con el apelativo de "doceta" (cf. infra, nota 21), pero ouros hablan con más propiedad en términos de "monofisitismo," cf. R.E. Brown, "The Kerygma of the Gospel according to Saint Jolun," Interpretation 21 (1967) 387-400, especialmente la nola 27 de la p. 399.

20. De hecho, en la exégesis reciente, esta polaridad se ha referido a las interpretaciones de $\mathbf{E}$. Käsemann (cl. nota siguiente) y R. Bultmann (Das Evangelium des Johannes, Gottingen, 18 [968). No pocos trabajos han intentado una salida a la alternativa que ofrecen estos dos autores (si de hecho esta alternativa resulta correcta o no, es olra cuestión que aqui no podemos (ratar). Sobre la misma puede verse la nota I9l de la p. 268 del trabajo "El cuarto evangelio: balance," cilado en la nota 12.

21. Como es bien sabido la formulación moderna de esı́e peligro se debe a E. Küsemann, El resıamenro de Jestís Salamanca, 1983 (original de 1966), pero otros han ido más lejos: L. ScholIrolf, Der Glaubenden und die feindliche Welt. Beabachlungen zum gnostischen Dualismus und seiner Bedeutung für Paulus und das Johannesevangelium, Neukirchen, 1970; M. Lattke, Einheit im Worl. Die spezifische Bedeurung von " "agapê," "agapan" und "philein" im Johannesevangetitum, München, 1975. Con todo se Irata de una interpretación que liene raices muy hondas en la historia de la exégesis joánica, cf. mi Irabajo: "El Quart evangeli, un evangeli herètic?," publicado en la obra Quatre comunilats davant Jesús, Barcelona, 1985, pp. 99-124.

22. Hay aqui una opción metodológica que no podemos justificar, pero que resulta hermenéuticamente muy importante. Para el EJ puede verse W.A. Meeks, "The man from heaven in Johannine Sectarianism," Journal of Biblical Literalure 91 (1972) 44-72, especialmente pp. 69-71.

23. Como es de sobra conocido esta "nueva búsqueda" del Jesús hislórico comienza en 1953 con la famosa conferencia de E. Käsemann y su camino llega a nuestros dias, a través de nombres tan conocidos como N.A. Dahl, G. Bornkamm, E. Fuchs, G. Ebeling, J.M. Robinson, eıc. Lo que resulıa interesante es recordar que E. Kassemann se refiere explicitamente al EJ en su primer manifiesto ("Das Problem des hislorischen Jesus," publicado ahora en Exegetische Versuche und Besinnungen, Gottingen, 1968 p. 201-202: auch für die johanneische Christologie die histarische Kontingenz und irdische Leiblichkeit des Offenbarers unverszichtbar ist) y que en su respuesta a Bultmann vuelve a insistir sobre lo mismo ("Sackgassen im Streint um den historischen Jesus', ibid. vol. II, pp. 31-68, y más en concreto p. 47). Que su postura haya cambiado (cf. El testamento de Jesús) es olra cuestión.

24. Puede verse mi trabajo: "El cuarı evangelio y la cuestión histórica," Estudios eclesiásticos 50 (1975) 55-76 y más en concreto pp. 63-66. 
25. X. Alegre, "Marcos o la corrección de una ideologia triunfalista. Para una leciura de un evangelio beligerante y compromelido," Revista Latinoumericana de Teologia 2 (1985) 229. 263, sobre todo pp. 247-249. Puede verse también E. Schweizer, "Die theologische Leistung des Markus," Evangelische Teologie 24 (1964) 342-355 (condensado en Selecciones de Teologia 9 (1970) 50-617.

26. Recordemos que esıos últimos años han visto aparecer una serie de obras sobre el concepto de historia en los sinópticos: J.M. Robinson, Das Geschichısverständnis des Markusevangeliums, Zürich, 1956; J . Rolofr, "Das Markusevangelium als Geschichısdarsiellung," Evangelische Theologie 27 (1969) 73-93; G. Stgrecker, "Das Geschichtsverstăndnisdes Matthäus, "Evangelische Theologie 26 (1966) 57-74; R. Walker, Die Heilsgeschichle im ersten Evangelium, Goltingen, 1967; H. Conzelmann, Die Mitre der Zeit. Studien zur Theologie des Lukas, Tübingen, 1954; K. Löning, "Lucas, teólogo de la historia de la salvación," publicado en la obra ediada por J. Schreiner, torma y propdsiro del Nuevo Tesiamento, Barcelona, 1973, pp. 236-268.

27. Cr. las obras citadas en la nota anterior.

28. El tema de la humanidad de Jesús en Hebreos ha sido objeto de atención por parte de la exégesis: M. Rissi, "Die Menschlichkeit Jesu nach Hebr 5.7-8," Theologische Zeilschrifl 11 (1955) 28-54; U. Luck, "Himmlisches und irdisches Geschehen im Hebräterbricf," Novum Testamentum; E. Grăsser, "Der Historische Jesus im Hebräcrbrief," Zeitschrifı für neutes-i Iamentliche Wissenschaft \$6 (1965) 63-91; J. Koloff, "Der mittleidende Hohepriester. Zuri Frage nach der Bedeutung des irdischen Jesus für die Christologie des Hebräerbriefes," publicado en el Festschrifı fiü H. Conzelmann (edit. G. Strecker), Jesus Chris/us in Hisıorie und Theologie, Túbingen, 1975, pp. 143-166; J.O. Tuñi, "Jesús en la carta als Hebreus," Butlleri de l'Associació Biblica de Calalunya, Suplement 4 (1984) 84-97.

29. Cr. J. Sobrino. "Hacia una determinaciòn de la realidad sacerdolal," Revisı Larinoamericana de Teología I (1984) 47-81, sobre lodo pp. 68-75.

30. Este es el objeto del estudio de E. Grässer, citado en la nota 28. supro.

31. Contra J. Roloff en el articulo cilado en la nota 28, quien irabaja a la luz del esquema de la historia salutis como marco del mensaje de Hebreos. Véase lo que decimos ell el trabajo "Jesús en la carla als Hebreus"' (nota 28). p. 96.

32. El rema de la realidad humana de Jesús en IPe. no ha sido objeıo de la atención que merece. Puede verse, sin embargo, lo que dice E. Kralt' en su trabajo "Christologie und An!hropologie im I.Petrusbrief." Evangelische Theologie $10(1950 / 51)$ 120-126, y mi aportación citada en la nola siguiente.

33. J.O. Tuñi, "Jesús of Nazareth in the Christology of IPc," que va a publicarse en Heythrop Journal (1987) y que esıá bosquejado en una ponencia pronunciada en las "Jornades de Bihlistes Catalans" (cF. Bulleti de l'Associacid Blblica de Calalunya 17 (198I) 14-25).

34. Pero no sólo para estos documentos, también para Pablo, en contra de lo que se asume ruiinariamente, liene Jesús de Nazarel una importancia grande. Pero esto no lo podemos desarrollar más aqui. Puede verse: G.N. Stanton, Jesus of Nazareth in New Testament Preaching. Cambridge, 1974 y X. Léon Dufour, Jesús y Pablo ante la muerte Madrid, 1982. Un resumen de la argumentación que puede hacerse en cste sentido: J.O. Tunti, "Jesús de Nazaret crimerio de identidad cristiana según el Nuevo Testamento," publicado en Revista de Pastoral Vocacinnal Todos Uno, 82, (1985), pp. 9-25, especialmente pp. 17-18.

35. Conviene recordar que esıa formulación se debe a A. Loisy (Le quearrième évangile, Paris, 1903), pero ha sido retomada por E. Kasemann (El ieslamento de Jestis).Cr. la nola 21 supra.

36. Hacer una reseña bibliográfica de este punıo, aunque fuera con criterios minimalistas, nos llevaria demasiado lejos. Puede verse el resumen de teorias que presenté en el boletin citado supra en la nota 16 (M.E. Boismard, R.E. Brown, J. Becker, G. Richter, J.L. Martyn, H. Thyen).

37. No escapan a este peligro los exegetas que, sin negar una historia del texto del EJ, miegan que pueda tener un in lujo importante en la interprelación del texio acabado del EJ.

38. Sobre el contenido de esta primera clapa estarian bastante de acuerdo los exegetas actuales, sobre todo después del estudio de R.T. Fortna sobre un mini-evangelio joánico que consıaria rundamentalmente de narraciones de "signos," The Gospel of signs, Cambridge, 1971, y el incisivo trabajo de R. Kysar, "The source analysis of the Fourth Gospel, a growing Consensus?" Novum Testamentum 15 (1973) 134-152; cf., del mismo autor, The Fourth Evangelist and his Gospel. An examination of contemporary Scholarship, Minnesota, 1975. 
39. W.A. Meeks, The Prophet-King. Moses Traditions and the Johannine Christology, Leiden, 1967, con las matizaciones que le ha hecho M. de Jonge, "Jesus as Prophet and King in the Fourth Gospel," publicado en su colección de ensayos Jesus, Siranger from heaven and Son of God. Jesus Christ and the Christions in Johannine Perspective, Montana, 1977.

40. D.M. Stnith, "The Setting and Shape of a Johannine Narrative Source," Journal of Biblical Literature 95 (1976) 222-248; "The Milieu of the Johannine Miracle Source: A Proposal," publicado en Jews, Greeks and Christians. Religious Cultures in Late Anriquity (Essays in honor of W.D. Davies), Leiden, 1976, pp. 231-241.

41. Cf. W.A. Meeks, en la obra citada supra, nota 39 y además K. Haacker, Die Stifrung des Heils, Stutigart, 1972, especialmente pp. 43-45 y 118-128 y su articulo "Gottesdienst ohne Gotteserkenntnis, Joh 4,22 vor dem Hintergrund der jüdisch-samaritanischen Auseinandersetzung," publicado en el Fesischrift. E.L. Rapp. Wort und Wircklichkeit, Meisenheim, 1976, pp. II0-126.

42. J. Blank, El Evangelio seguin San Juan 4,2, Barcelona, 2 1984, p. 11.

43. X. León Dufour, "Le signe du temple selon Sainı Jean," Recherches de Science Réligieuse 39 (1951) 155-175.

44. C.K. Barrell, The Gospel according 1o St. John. An introduction with commentary and notes on the Greek text, London, 21978.

45. R. Schnackenburg, El evangelio según San Juan, vol. 1Il, Barcelona, 1980, pp. 386-387.

46. Sobre este relevante aspecto del comienzo del cristianismo se podria citar una literatura inacabable. Nos limitaremos a señalar un articulo muy penetrante de N.A. Dahl, que hemos usado en la versión inglesa: "Eschatology and History in the Light of the Dead Sea Scrolls," publicado en el Fesischrift. R. Bultmann, The Future of Religious Past, editado por J.M. Robinson, London, 197I, pp. 9-28, especialmente pp. 23-24.

47. X. León Dufour," Actualité du quatrième ávangile," Nouvelle Révue Théologique 76 (1954) 449-468 y tambièn "Towards a symbolic reading of the Fourth Gospel," New Tesiament Siudies 27 (1981) 439-456, especialmente pp. 443-445.

48. Dice un comentarista contemporáneo al analizar Jn. 7,39: Diese Auffassung der johanneischen Gemeinde legt ihr Selbstverständnis frei: Sie ist die Gemeinde aus dem Geist des Erhbhlen $(14,16 f . ; 20,22 ; \mathrm{vgl}$. 2,2J). Dies ist so betont, dass sie sich selbst absetzl von der vorösterlichen, Situation, denn deren Geistmangel ldsst Christentum in strengen. Sinn erst mit der Erhohung Christi beginnen. Christentum ist konstituiert durch den im Geist prtsenten Christus als Quelle des Lebens, J. Becker, Das Evangelium des Johannes, vol. I, Würzburg. 1979, p. 276.

49. R. Bultmenn, Das Evangelium des Johannes, Gobltingen, 18 1964, p. 485 nola I; cr. R.E. Brown, El evangelio según San Juan, XIII-XXI, Madrid, 1979. p. 901 y 903-904.

50. Este punto no ha escapado a la percepción exegética de los especialistas y se está constituyendo en un tema verdaderamente central de la interpretación joánica. Puede verse lo que deciamos en el trabajo cilado en la nola 16, pp. 72-73, y además el penetrante irabajo de $\mathbf{R}$. Schnackenburg, "Die johanneische Gemeinde und ihre Geistcrfahrung" publicado en el Fesischrifi. H. Schurmann, Die Kirche des Anfongs, Leipzing, 1977, pp. 277-306.

31. Puede verse una exposición más delallada de lo que sigue en J.O. Tuñi, "Creure en Jesús (Jn. 12,I1). Reflexions sobre l'objecte del pisteviein de Joan," Revista Caralana de Teologia 9 (1984) 331-358.

52. Decia C.K. Barrell en la primera edición de su comentario a raiz de Jn. 8,30: "Estas referencias a 'muchos' creyentes han de tomarse como el gnôsesthe de 8,28 como referencias a un tiempo distinto del tiempo del ministerio de Jesús," The Gospel according 10 St. John, London, 1955, p. 284. No deja de ser interesante y significativo que este comentario ha desaparecido en su edición de 1978 .

53. El 'último dia' es una expresión de la tradición que adquieren unas connolaciones crisıológicas muy notables en el EJ. De hecho, el úlıimo dia está subordinado a Jesús. Por ello, la corrección de Jesús a la fe de Marta ("ya sé que mi hermano resucilará el último dia") no se hace invocando otra concepción cronológica, sino la realidad del mismo Jesús ("yo sny la resurrección y la vida," Jn. II,25; $c \Gamma .11,24$ ); puede verse mi (rabajo, "El cuarto cvangelio y el tiempo. Notas para un estudio de la concepción del tiempo en el cuarıo evangelio," Estudios Eclesiósticos, 57 (1982) 129-154. 
54. To a certain extent extent 'knowing' and'believing' are interchangeable in John (R. E. Brown, The Gospel according to John I-XII, New York, 1966, p. S13); C.K. Berrett viene a decir casi lo mismo: The verb'pisteuein' is used almost sinonimously with gindskein', The Golpel acoording 10 St. John, p. 68; "especialmente frecuente es el empleo de ginóskein y su afinidad con pisteuiein se ha observado y examinado muchas veces," $R$. Schnackenburg, El evangelio según San Juan, vol. I, Barcelona, 1980. p. 550, etc.

55. Puede verse mi trabajo: La verdad os hará libres (Jn. 8,32), Barcelona, 1973, pp. 139-147.

56. 'Pistejein' und 'ginóskein' sind bei John nicht hinsichtlich ihres Gegenstandes verschieden...

Das 'ginoskein' kann sich nicht vom 'pisteúein' IJsen, das 'pisteuiein' muss aber als echles zugleich ein 'ginoskein' sein; d.h. das Erkennen ist ein Struckturmoment des Galubens, $R$. Bultmann, Das Evangelium des Johannes, p. 333, nota 6.

57. Este aspecto está desarrollado con mucha más amplitud en una obra mia en prensa: Jesús y el evangelio en la comunidad jodnica. Introducción a la lectura cristiana del evangelio de Juan. Salamanca, 1986.

58. Véase lo que decimos en el trabajo citado supra, en la nota 53, especialmente el análisis del tema de la 'hora' de Jesús, pp. 139-140.

59. G. Segalla, Volunsa di Dio e dell'uomo in Giovanni, Brescia, 1974.

60. Cr. W. O'Connell, "The Concep1 of Commandment in the Old Testament," Theological Studies 21 (1960) 351-403; J.O. Tuñi, "Amar como Jesús. Sentido del mandamiento del amor en el cuario evangelio," Sal Terrae, octubre de 1982, pp. 717-728.

61. Este tema ha sido especialmente analizado en estos últimos años. Los estudios más importantes: P. Borgen, "God's Agent in the Fourth Gospel," publicado en la obra editada por J. Neusner, Religions in Antiquity, Leiden, 1968, pp. 137-148; J. Bühner, Der Gesandie und seis Weg in 4. Evangelium. Tübingen, 1977; J.P. Miranda, Die Sendung Jesu im vierten Evangelium, Stutigart, 1977.

62. Un resumen más extenso de este importante tema puede enconırarse en mi obra El testimonio del evangelio de Juan. Introducción al estudio del cuario evangelio, Salamanca, 1983, pp. 135-143.

63. La formulación cs de T. Onuki, Gemeinde und Well im Johannesevangelium. Ein Beitrag zur Frage nach der theologischen und pragmatischen Funkrion des johanneischen Dualismus', Neukirchen, 1984, p. 204 (con referencia a la obra de J. Blank, Krisis. Untersuchungen zur johanneischen Christologie und Eschatologie, Freiburg i.B., 1964, pp. 267-273). Pero no se trata de una a/irmación colateral, es el verdadero punto de apoyo de toda su tesis. Este aspecto lo he recogido y ampliado en la obra citada supra, nota 57.

64. Aspecto que he subrayado ell el trabajo "Creure en Jesús ( Jn $(2,11)$," citado en la nota 51 y en el libro citado en la nota 57 supra.

65. Esta afirmación es de E. Haenchen: Aber gerade dieser Offenbarer, dieser Gesandte Gottes findel nun bei seiner irdischen Wirksamkeil keinen Glauben. Das ist eine Tatsache dass der Leser des JE leicht übersiehı, en su obra póstuma, Johannesevangelium. Ein Kommentar (cd. U. Busse), Tübingen, 1980, p. 575 (vèase también lo que dice en la p. 108 sobre el mismo (ema).

66. Esto lo he desarrollado en un trabajo que va a publicarse en el volumen que conmemora los XXV años de Jornades de Biblisles Calalans. "La salvació ve dels jueus (Jn. 4,22). Valoració del Judaisme des del quart evangeli" (en prensa, Barcelona, 1987).

67. $Y$, por otra parte, se implica aqui una acusación de ditésmo por parte de la sinagoga farisea, que resulta fundamental para comprender el EJ. Esio lo ha trabajado especialmente J.L. Marlyn, History and Theology in the Fourth Gospel, New York, 1968, pp. 45-68. R.E. Brown se hace eco de este aspecto en su reciente análisis de la historia de la comunidad joànica: La coniunidad del discipulo amado, Salamanca, 1983 (original de 1979).

68. Esta distinción resulta fundamental en la tesis de T. Onuki para deslindar las interpretaciones de Bultmann y Kásemann. Si Bulımann atiende fundamentalmente a la reflexión crisıológica de la comunidad y Kassemann quicre presentar sólo el misterio de Jesús, enıonces sus interpretaciones del EJ no se oponell. Pero ambas resultan parciales. Ver Gemeinde und Welt, (citado cn la nota 63), p. 185-213, más en concreto pp. 185-187. 188-193. 193-197.

69. L.a legirimidad de esta confesión no nos lleva a una interpretación gnóstica del EJ. Más bien hay que recordar que estamos en un contexto judio, en el corazón de la confesión judia: cf. "El cuarto evangelio y el tiempo," citado en la nota 53, pp. 150-154 y las referencias que allá 
se hacen a la actualización de los sucesos salvificos de la mano del que, con G. von Rad, podemos llamar "credo histórico."

70. La formulación "implicación cristológica" se debe a J. Blank en su obra Krisis: Die Christologie ist nun aber auch nicht zu verstehen ohne die Christusgeschichte. Wir haben dafiur des Begriff 'christologischen Implikation' geprdggl, und wir verstehen darunter die nichr aufzulosende Einheit von Person und Geschichre in Jesus Chris/us, op.c. (nota 63 supra), p. 347 . Sin embargo, Blank habla fundamentalmente de implicación cristologica entre el exaltado y el terreno. Con razón T. Onuki objeta que esta implicación se ha de alargar hasta la preexistencis: Gemeinde und Welt (citada en la nota 63 supra), pp. 207-211.

71. Es W. Thusing quien, en sy conocida obra Die Erhohung und Verherrlichung Jesu im Johannesevangelium, Munster, 2 1970, habla de 'interpenetración o interproyección' de las etapas cristológicas. Sin embargo, la presentación de Thusing, a pesar de las correcciones que le han impuesto E. Kussemann y J. Blank, resulıa excesivamente dependiente de un esquema histórico, como acertadamente dice T. Onuki: Gemeinde und Well, pp. 195-199.

72. Para la figura del 'hijo del hombre' como representativa de la concepción cristológica, cf. los trabajos de J. Blank y T. Onuki. Sin embargo, hay que tener tambiên en cuenta lo que dice sobre la misma F.J. Moloney, The Johannine Son of Man, Roma, 1976, cf. la nota siguiente.

73. Es F.J. Moloney quien, en su tesis doctoral citada en la nota anterior, insiste en el acento del EJ en la realidad terrena del 'hijo del hombre' joánico. El no tener en cuenta lo que hemos Jlamado (con J. Blank) implicación crisıológica hace que su interpretación de la figura de 'hijo del hombre sea unilateral.

74. Retomamos aqui, en un contexto distinto, y, por tanto, con un valor distinto, mucho de lo que ya dijimos en la obra El restimonio del evangelio de Juan. Una iniraducción al estudio del cuario evangelio, Salamanca, 1983, pp. 107-114.

75. John intended to provide evidence that Jesus was a real man, and that he really died, C.K. Barrell, The Gospel according to St. John, London, 1955, p. 462; the spear-thrust cannot be intented to cause death, but to certify it, B. Lindars, The Gospel of John, London, 1971, p. 586; In der Durchbohrung und in Blur und Wosser geht es also zunächst um das echte und volle Menschsein Jesu und um die Realisdt seines Todes, J. Heer, Leben hat Sinn. Christliche Existenz nach dem Johannesevangelium, Stultgart, 1974, pp. 108-109. Puede verse tambièn J.O. Tuñi. "Pasión y muerte de Jesús en el cuarto evangclio: papel y significación," Revisia Calalana de Teología / (1976) 393-4/9.

76. Como hemos indicado anies (supra, nola 74) se reloman aquí muchos datos esbozados en la obra El restimonio del evangelio de Juan, pero lo que alli no se decia es precisamente lo que constituye el núcleo de la argumentación de estas páginas: la realidad del Jesús terreno se ejemplifica a través de los datos que describen su vida, pero en realidad su afirmación se da en el contexto de la confesión. Es decir, en el contexio de la docırina del EJ. Tal vez la formulación del evangelio que más profundamente recoge esta realidad son las afirmaciones sobre el nombre de Jesús: creer en su nombre y rogar en su nombre. Puede verse en este sentido F. Untergassmair, Im Namen Jesu. Der Namensbegriff im Johannesevangelium, Stutigart, 1974.

77. Ya R. Bultmann en su comentario decia que los gestos de Jesús son "redente Taten," hechos que hablan, ef. Das Evangelium des Johannes, pp. 346.491.541. Puede verse tambièn lo que decimos en el trabajo: "Fe i sacramentalitat en el quart evangeli," en Qüestions de Vida Cristiana 61 (1972) 15-27.

78. La confesión del centurión en Mc. 15,39 acerca grandemente el evangelio de Marcos al EJ en este punto. Pero no es sólo en este aspecto que estas dos obras muestran una profunda sintonia: en su entramado hermenéutico fundamental estas dos obras se hallan en gran consonancia. Tal vez en esto muestran su radical filiación judia, pero este punto cae fuera de nuestro objetivo y merece una atención que aqui no podemos prestarle. Si se menciona en nola es por su transcendencia de cara a la lectura de los evangelios (sobre todo si tenemos presente la hipótesis de las dos fuentes en la tradición sinóptica).

79. Los textos del EJ son: 5,$19 ; 8,26 ; 8,28 ; 12,49 ; 15,15$; en todos ellos se habla de lo que se ha visto u oido "junlo al Padre."

80. Hay que tener en cuenta aqui lo que hemos dicho más arriba sobre la imagen del "hijo del hombre," cf., además las notas 72 y 73 supra. 
B1. Ver la nota 67 supra. Este aspecto habia sido trabajado por $R$. Bultmann en su comentario (y lambién en Theologie des neuen Testaments, Tubingen, 6 1968, pp. 392-402; 427-445) y ha pasado a ser un punto de referencia fundamental en la exégesis del EJ: es el tema del escandalo de la encarnación. Pero Bulımann lo cenıró fundamentalmente en la fe joánica como fides qua creditur, olvidando que el acento fundamental esıá en el nivel de la fides quae creditur, cf. T. Onuki, Gemeinde und Welt, 185-187.193-196 y E. Käsemann, El tesıamento de Jesús, 45-47.71-74.

82. "Pasión y muerte de Jesús en el cuarto evangelio; papel y significación," citado en la nota 75 , sobre todo pp. 396-408.

83. La importancia y centralidad de este texto para la exégesis joánica contemporánea puede verse en el minucioso examen del mismo de $\mathbf{H}$. Thyer como capitulo central de su dilatado boletin bibliográfico "Aus der Literatur zum Johannesevangelium," publicado en Theologische Rundschau 39 (1974) 53-69; 222-252. Una justificación más especifica de nuestro argumento acerca de 1,14 puede encontrarse en El testimonio del evangelio de Juan, p. 143-145.

84. El restimonio del evangelio de Juan, p. 106.

85. La epistemología y la hermenéutica juegan aqui un papel fundamental. Pero ya hace tiempo se viene diciendo que la hermenéutica que mejor expliea la óptica del EJ es la de H.G. Gadamer, Verdad y mérodo, Salamanca, 1977 (original de 1960). Aplicada al EJ, F. Mussner, Die johanneische Sehweise und die Frage nach den historischen Jerus, Freiburg i.B., 1965 y T. Onuki, Gemeinde und Well (cilado en la nota 63 supra). Puede verse también lo que digo en la obra Jesús y el evangelio en la comunidad joánica (citada supro en la nota 57).

86. Un incisivo y critico análisis de este género literario y de su utilización en el Nuevo Testamento puede encontrarse en E. Cortés, Los discursos de adios de Gen. 49 a Jn. 13-17, Barcelona. 1976.

87. Esta descripción del Jesús joánico se halla ya en el comentario de R. Bulımann, Das Evangelium des Johannes p. 432. Vèase también lo que dice $H$. Schlier a este propósito en su sugerente trabajo: "Zur Christologie des Johannesevangelium," aparecido en Dos Ende der Zeil (Exegetische Aufsatze und Vorträge (II) Freiburg i.B., 1971, pp. 85-101, especialmente p. 94. Tambièn T. Onuki ha recogido esta presentación, Gemeinde und Well, p. 111.

88. Aunque, a lo que parée, sólo en tiempos del Nuevo Testamento se constituye en género literario, si hemos de hablar con propiedad. Cl. la obra de E. Corlés citada en la nota 86.

89. Este aspecto ha sido especialmente puesto de relieve por $X$. Lèon Dufour en su estudio de las pericopas de la inslitución de la eucaristia, La fracción del pan. Culro y existencia cristiana en el Nuevo Tesiamento. Madrid, 1983, sobre codo pp. 125-129 y 310-345.

90. Como resulıa bien conocido, los discursos de despedida de Jesús en el EJ han sido objelo de especial alención estos últimos años: "La investigación joánica en el decenio 1974-1983," citado en la nola 16, pp. 79-80. Por olra parte, algunos autores verian en estos fragmentos hasta Ires sucesivas capas literarias: J. Becker, "Die Abschiedsreden Jesu im Johannesevangelium," Zeitschriff füir neufestamentliche Wissenschatf 6I (1970) 215.246.

91. Este punto resulta casi un aspecto adquirido de la exégesis joánica. Puede verse R.E. Brown, "The Paraclete in the Fourth Gospel," New Testament Studies 13 (1967) 113-132; R. Schnackenburg, "Die johanneische Gemeinde und ihre Geisterfahrung," publicado en el Festschrift. H. Schürmann, Die Kirche des Anfangs, Leipzig, 1977, pp. 277-306; S. Migliasso,La presenza dell'assente. Saggio di analisi letterario-structurale e di sintesi teologica di Gv 13,31 14,3I, Roma, 1979.

92. T. Onuki, Gemeinde und Well, p. 166.

93. Ibid., pp. 163-166.

94. Ver mi presentación "Amar como Jesús," citada en la nola 60 supra. Allá se trata el tema más ampliamente.

95. Que el amor es en el EJ, por encima de todo, donación se puede constatar ell textos como: "El Padre ama al hijo y se lo enirega lodo" $(3,35)$; "para que conlemplen ni gloria, la que me has dado porque me has amado desde antes de la creación..." $(17,24)$; "no hay amor más grande que dar la vida por aquellos a quienes se ama" (15,13). La IJn. hará codavia más explicito que amar consiste fundamentalmente en dar ( $y$ más en concreto en dar la vida).

96. Esto ro sólo lo dicen los comentarios en general, sino que lo ha mostrado convincentemente O. de Dinechin, "Kathôs: la simililude dans l'évangile selon Saint Jean," Recherches de Science Réligieuse 58 (1970) 195-236. Cr. E.A. Abboll, Johannine Grammar, London, 1906 s.v. kathôs. 
97. Incluso semánticamente queda esto subrayado en el EJ: lo que Jesús entrega es su vida terrena (Psyche): puede verse mi trabajo, "Antropologia en els escrits joànics," Butllesl de l'Associació Blblica de Catalunya, Suplement 2 (1982) 86-98, sobre todo pp. 93-95.

98. Conviene recordar que la expresión "agapê tou theou" en los escritos joánicos designa primaria y fundamentalmente el amor con que Dios ama al hombre y no el amor con que el hombre ama a Dios: "Creer en el amor (1 Jn. 4,16a). Relación entre creer y amar en la 1Jn," que va a aparecer en el curso de este año en la obra en colaboración "La venda en los ojos" (itulo provisional), Sal Terrac, Santander, 1986.

99. Esto va direciamente contra M. Lat1ke (en la obra citada en la nota 21 supra) quien, siguiendo a E. Kàsemann, definirla la unidad como "solidaridad de lo celestial," sin relación alguna con el mundo. La palabra solidaridad ciertamente es correcta, pero aplicada a la relación de los hombres entre si y, por tanto, como fruto del amor de Dios. Este tiende a crear solidaridad entre los hombres, la cual será una reproducción de la realidad de Dios. Esto lo hemos desarrollado más en el trabajo cilado ell la nota anterior.

100. Resulta sorprendente que el terna del simbolismo, con ser un tema perenne de la interpretación joánica (cf. el comentario de Origenes y sus matizaciones a la interpretación de Heracleón), no haya encontrado todavia quien lo trate en profundidad. Lo más interesante y prometedor en este sentido lo ha escrito $X$. Leon Dufour, "Towards a symbolic reading of the Fourth Gospel," citado supra en la nota 47. El trabojo de G. Siemberger, La symbolique du Bien et du Mal selon Saint Jean, Parls, 1970, resulta interesante, pero insuficiente.

10l. Sería més acorde con las presentaciones neotestamentarias hablar de "gestos y palabras de Jesús" más que de "historia," porque, de hecho, con este concepto parece que implicamos que ya para los autores neotestamentarios existía un concepto acuñado y común. Ver lo que hemos dicho en este sentido en la introducción de este trabajo y las refletiones finales det articulo sobre la carta a los Hebreos citado en la nota 28 supra.

102. Para lo que sigue puede verse mi trabajo "El cuarto evangelio y el tiempo," citado supro en la nota 53. La presentación cristologiea de J. Blank en Krisis (cf. nota 63 supra), viene a coincidir fundamentalmente con nuestro punto de vista. Todo esto ha sido mucho más desarrollado en el libro cilado en la nola 57 supra.

103. De aqui que, a pesar de los rasgos "personales" que lo caracterizan, resulta tan diflcil de identificar. Pero este trazo es bien patente en toda la historia de la pneumatologla.

104. Esıe ıema (por qué escribió la comunidad joénica precisamente un "evangelio") ha sido profundamente tratado por T. Onuki, Gemeinde und Well, pp. 201-213, con referencias muy precisas al cambio de punto de vista de E. Kasemann (cI. ibid., p. 201 y las notas de dicha pdgina).

105. Que el evangelio quiere comunicar la experiencia de la fe, se dice expllcitamente en la conclusión: "estos (signos) se han escrito para que crean que Jesús es el Mesias y el hijo de Dios" (20,30-31). Pero, además, este elan misionero resulta un aspecto esencial del mensaje jó́nico y de la redacción del EJ precisamente con la forma de "buena nueva." Lo que ocurre es que el EJ resulta más bien la concreción de una reflexión comunitaria que quiere reafirmar su propia identidad en frente de una persecución bien patente (15.18-16, 4a). Por ello en otro lugar hemos definido esia obra como un retiro espiritual de la comunidad (Jesús y el evangelio en la comunidad jod́nica, citado en la nola 57 supra). De hecho, la situación vital que presupone es la de un grupo que intenta reafirmar sus raíces. Pero ello no lo conviente automaticamente en un grupo sectario como algunos parecen afirmar: W.A. Meeks, "The man from heaven in Johannine Sectarianism." citado en la nota 22 supra y sobre todo los autores y obras citados en la nota 21 supra. En cambio, la interpretación de H. Leroy, Ratsel und Missverstandnis, Bonn, 1968, apunta en la.dirección correcta.

106. Recordemos el ejemplo de la carta a los Hebreos que hemos presentado en la introducción. Ahi tampoco el esquema de historia salutis ha sido utilizado como vehiculo leologico, porque una cosa es contar con este esquema y otra utilizarlo teológicamente; puede verse mi trabajo "Jesús en la carta als Hebreus," citado en la nota 28 supra, pp. 96-97.

107. Esto se deberia delallar más, pero aqui nos llevaria demasiado lejos. Puede verse lo que escribi acerca de este tema en "Jesús de Nazaret, criterio de identidad cristiane según el Nuevo Testamento," cilado en la nota 34 supra.

108. Una justificación de esta afirmación puede encontrarse en el Boletín bibliografico: "La investigación joánica en el decenio 1974-1983," citado en la nota 16, especialmente pp. 47-67. 
109. Lo hemos tratado en los articulos: "Motivaciones étiques de la 1Jn: la IJn i el Jesús històric." publicado en Revista Catalana de Teologia 3 (1979) 285-308; "Creer en el amor (I Jn, 4,16a). Relación entre 'creer' y 'amar' en la 1 Jn." que va a publicarse en la obra en colaboración "La venda en los ojos" (titulo provisional), Santander, 1986.

110. Ver "Motivacions ériques de la I Jn: la I Jn i el Jesús históric," citado en la nola anterior, pp. 288-289.

111. V.H. Neufeld, The earliesı Christian Confessions, Leiden, 1963, pp. 90-91; K. Wengst, Haresie und Orthodoxie im Spiegel des ersien Johannesbriefes, Gutersloh, 1976, pp.20-22; 64; U.B. Milller. Die Geschichte der Christologie in der johanneischen Gemeinde, Stuttgart, 1975. pp. 57.62 .

112. Este uso enfático de ekeinos en la $1 \mathrm{Jn}$. (cf. "Molivacions éliques citado en la nota 109, pp. 291-292) no está desligado de la enfálica presentación de Jesús en el EJ. Más bien, al reves, es una muesıra de que la cenıralidad del mismo Jesús es una realidad en esta comunidad: cf. Jesús y el evangelio en la comunidad joánica, citado supra en la nota 57.

113. También los 98 lugares donde se usa este verbo en el EJ tienen como objeto a Jesús o sus palabras o son confesiones de Jesús como el que ha salido de Dios, etc. Ver para todo esto (que resulta bien conocido), El testimonio del evangelio de Juan, citado en la nota 62, pp. 176. 180.

114. Los textos que expresan las opiniones de los adversarios son introducidos con las expresiones: "si decimos..." (I Jn. 1,6.8.10); "el que dice..." (I Jn. 2,3.6.9) y tambien "si alguien decia..." (I Jn. 4,20). Un resumen suficientemente matizado de su posición puede encontrarse en R. Schnackenburg, Carias de San Juan. Version, introduccion y comentario, Barcelona, 1980, pp. 58-66. Y lambién en R.E. Brown, The Epistles of John, New York, 1983, pp. B3-115.

115. Puede verse, en la $1 \mathrm{~J} n ., 2,3.5 ; 3,16.19 .24 ; 4,2.6 .13 ; 5,2 ;$ y también 3,10 . Un análisis del sentido de los mismos en K. Wengst, Haresie und Orhodoxie, citado en la nota 111 supra, pp. 12 y nota 6 de la p. 13.

116. Cr. I. de la Potterie, "La notion de commencement dans les terits johanniques," publicado en el Fesischrift. H. Schurmann, Die Kirche des Anfangs, Leipzig, 1977, pp. 379-403; R. Bultmann, Die drei Johannesbriefe, Götingen, 1967, p. 15.

117. Esta es la conclusión del trabajo "Creer en el amor (1 Jn. 4,168)," citado en la note 109 supra y que está en prensa. 